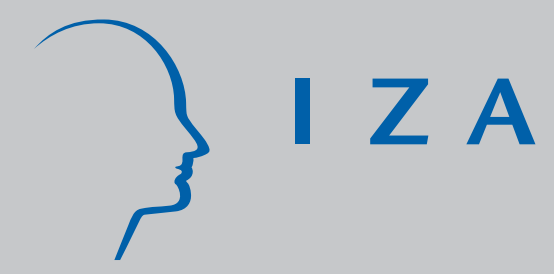

IZADP No. 2702

Income Satisfaction and Deprivation in Spain

J osé M. Labeaga

J osé Al berto Molina

María Navarro

March 2007 


\title{
Income Satisfaction and Deprivation in Spain
}

\author{
José M. Labeaga \\ FEDEA and UNED, Madrid
}

José Alberto Molina

University of Zaragoza and IZA

\author{
María Navarro
}

FEDEA, Madrid

\section{Discussion Paper No. 2702 \\ March 2007}

\author{
IZA \\ P.O. Box 7240 \\ 53072 Bonn \\ Germany \\ Phone: +49-228-3894-0 \\ Fax: +49-228-3894-180 \\ E-mail: iza@iza.org
}

\begin{abstract}
Any opinions expressed here are those of the author(s) and not those of the institute. Research disseminated by IZA may include views on policy, but the institute itself takes no institutional policy positions.

The Institute for the Study of Labor (IZA) in Bonn is a local and virtual international research center and a place of communication between science, politics and business. IZA is an independent nonprofit company supported by Deutsche Post World Net. The center is associated with the University of Bonn and offers a stimulating research environment through its research networks, research support, and visitors and doctoral programs. IZA engages in (i) original and internationally competitive research in all fields of labor economics, (ii) development of policy concepts, and (iii) dissemination of research results and concepts to the interested public.
\end{abstract}

IZA Discussion Papers often represent preliminary work and are circulated to encourage discussion. Citation of such a paper should account for its provisional character. A revised version may be available directly from the author. 


\section{ABSTRACT}

\section{Income Satisfaction and Deprivation in Spain ${ }^{*}$}

The first objective of our paper is to identify the determinants of income satisfaction in Spain, with one of these being relative deprivation, and the second is to measure this relative deprivation, in both monetary and satisfaction terms. To that end, we use data from the eight waves of the Spanish section of the European Community Household Panel (1994-2001). With respect to the first objective, we estimate models for categorical variables in order to test whether subjective satisfaction measures depend on relative deprivation, as well as on other determinants. As for the second objective, we first calculate inequality and polarization indices and then we specifically analyze whether the Spanish tax-benefit system helped to reduce individual deprivation. Our results suggest that the more unequal the income distribution is in a group, the less income satisfied is the individual. Moreover, being unemployed is one of the main determinants of deprivation, although public transfers help to reduce individual deprivation. When we observe the amount of public transfers received, deprivation is reduced up to a certain threshold, beyond which it continues to decline, but at a lower rate.

JEL Classification: D31, D63, I31

Keywords: income satisfaction, deprivation, inequality, polarization, Spain

Corresponding author:

José Alberto Molina

Department of Economic Analysis

University of Zaragoza

Gran Vía 2

50005 Zaragoza

Spain

E-mail: jamolina@unizar.es

\footnotetext{
* This research was conducted while María Navarro was Visiting Fellow at the Fundación de Estudios de Economía Aplicada (FEDEA). I am very grateful for the hospitality and facilities provided. I am indebted to comments from participants at the XXXI Simposio de Análisis Económico and in a seminar at FEDEA and specially to Namkee Ahn and Juan Ramón García. The authors would also like to express their thanks for the financial support provided by projects SEJ2005-08793-C04-04, SEJ200506522/ECON and the Aragon Government grant B168/2003. The usual disclaimer applies.
} 


\section{Introduction}

It is a fact that the general satisfaction of individuals has been extensively studied by psychologists (Diener et al., 1999; Kahnemann et al., 1999), and the existing state of research further suggests that reported subjective well-being is a satisfactory empirical approximation for individual utility that can be applied in socio-economic research (Oswald, 1997; Easterlin, 2002; Frey and Stutzer, 2002; Hamermesh, 2004). On this basis, one particular aspect of individual satisfaction that has been the subject of extensive analysis in the literature is satisfaction derived from income, with the evidence to date showing that age, education and individual income appear to have significantly positive impacts on individual income satisfaction (Burkhauser et al., 1997; Osberg and Sharpe, 2002; Bonke and Browning, 2003; Ferrer-i-Carbonell and Van Praag, 2003; Schwarze, 2003; Clark et al., 2004; D’Ambrosio and Frick, 2004).

In this context, although inequality in income levels of individuals usually gives rise to a degree of dissatisfaction in the population, neither the traditional inequality indices, nor the new polarization indices, are able to show with precision the level of well-being in society as a whole, or in different sub-populations. Thus, it becomes necessary to complement traditional measures with alternative deprivation indices (Esteban, 1996; Podder, 1996). There are several relative deprivation measures proposed in the literature which constitute excellent indicators of individual satisfaction, with these measures expressed in relative terms, that is to say, by way of comparison among individuals belonging to particular sub-populations (Yitzhaki, 1982). ${ }^{1}$ For instance, the relative deprivation in terms of income should be characterized as the difference between the income of an individual and the average income of the individuals within his subgroup who have higher incomes. Thus, one of the concerns of deprivation measurement is to adequately define the reference groups, since an individual can belong to several overlapping sub-populations, and the measures can vary in terms of the number and composition of the groups (Gradín, 2000).

Up to now, the majority of analyses of relative deprivation have focused on income levels, in this way characterising a number of poverty indices, closed related to the Gini index, which show the relative deprivation suffered by those individuals whose incomes are below some fixed thresholds (Sen, 1973, 1976; Takayama, 1979).

\footnotetext{
${ }^{1}$ These reference sub-populations have been analyzed from different viewpoints in the economic literature, e.g. Duesenberry (1949) from the relative consumption theory or Buchanan (1965) from the theory of clubs. Recently, Barret and Esteban (2005) have surveyed the literature on reference groups.
} 
However, the fact that this Gini index is not consistent with every well-defined welfare function (Atkinson, 1970, Dasgupta et al., 1973; Lambert, 1985), has given rise to some generalizations (Yitzhaki, 1979; Kakwani, 1984; Chakravarty and Chakraborty, 1984; Paul, 1991). For example, the deprivation index proposed by Yitzhaki (1979) is derived as the product of the average income and the Gini coefficient, with a generalization of this being proposed by Chakravarty and Chakraborty (1984). These studies do not allow individual deprivation to be sensitive to income transfers among those who are richer, with this concern being later resolved by the individual deprivation function proposed by Paul (1991).

In this context, the first objective of our paper is to identify the determinants of income satisfaction in Spain, with one of these being relative deprivation, and the second is to measure this relative deprivation, in both monetary and satisfaction terms. To that end, we use data from the eight waves of the Spanish version of the European Community Household Panel (1994-2001). With respect to the first objective, we estimate models for categorical variables in order to test whether subjective satisfaction measures depend on relative deprivation, as well as on other determinants. ${ }^{2}$ As for the second objective, we first calculate inequality and polarization indices, both for the population as a whole and for subgroups formed using several demographic variables, and then we specifically analyze whether the Spanish tax-benefit system helped to reduce individual deprivation, in both monetary and satisfaction terms. Prior to these two analyses, and given that inequality and polarization indices behave in a significantly different way from those of deprivation, we calculate these three indices for the population as a whole, and for sub-groups defined by several different demographic variables.

In addition to this new approach, analysing the link between the two objectives of the paper, another contribution to existing studies lies in our definition of the reference groups. To this end, we try three definitions, based on potentially exogenous variables, in order to check the sensitivity of the results to different alternatives. First, we establish individual comparisons with respect to members of groups of the same gender and education level. Second, we compare individuals of the same gender and age group. Third, we compare individuals belonging to groups of the same gender, age and

\footnotetext{
${ }^{2}$ Chakravarty and Mukherjee (1999) were the first to link indices of deprivation with social satisfaction. Subsequently, Frick and D’Ambrosio (2004) also analyzed the relation between individual satisfaction and deprivation.
} 
education level. In this way, we have constructed 6, 8 and 24 different and nonoverlapping sub-populations.

Section 2 is devoted to presenting some empirical evidence on income distribution in Spain. We then move on to describe the dataset, as well as to present the empirical specifications in section 3. In Section 4 we explain the main results and some policy implications and, finally, Section 5 contains our conclusions.

\section{A first look at income inequality, polarization and deprivation in Spain}

We begin by examining income distribution in Spain, between 1994 and 2001, by using both the inequality and polarization measures. Studies of inequality and polarization before the appearance of the ECHP were based on data from the Spanish Household Expenditure Surveys, conducted for the years 1973/4, 1980/1 and 1990/1. Inequality has been reduced in Spain from the second half of the 1990s (Oliver et al., 2002), and evidence on polarization with 2, 3 and 5 sub-populations, presented in Gradín (1999), found a depolarizing trend throughout the 1980s and the 1990s.

In technical terms, an inequality index is a convex linear combination, weighted by frequencies, of several ways of evaluating income differentials (Esteban, 1996). A polarization index is a convex linear combination of evaluations of frequencies, where the weights are the relative differentials. Thus, inequality measures are especially sensitive to income differentials and linear in frequencies, while polarization measures are sensitive to frequencies and linear in income differentials. When we measure polarization from data previously grouped in income intervals, these indices are much more volatile than those of inequality (Esteban, 1996). Such volatility is sensitive to the number of income groups chosen, it would be less so if there were fewer groups, for example, 2 groups instead of 6. The Lorenz criteria cannot distinguish if the population is concentrated around one global average or several local poles, so that it is possible that a given population with less inequality is concentrated around a small number of poles that are widely separated.

Since inequality cannot show the social tension in a particular situation, it is necessary to complement the inequality results with polarization measures. Esteban and Ray (1994) defined a polarization measure where individuals who belong to each of the groups are identified with the members of their group, and they feel alienated regarding 
the members of other groups: $E R\left(\gamma, \rho^{\prime}\right)=\sum_{i=1}^{n} \sum_{j=1}^{n} \pi_{i}^{1+\gamma} \pi_{j}\left|\ln y_{j}-\ln y_{i}\right|$. Then, Esteban et al. (1999), who introduced an extension of the Esteban and Ray (1994) polarization approach, allows us to deal with distributions that were not previously organized in groups: $P\left(F ; \gamma, \lambda, \rho^{\prime}\right)=E R\left(\gamma, \rho^{\prime}\right)-\lambda\left[G(F)-G\left(\rho^{\prime}\right)\right]$ where $\mathrm{F}$ is the income distribution and $\gamma$ is the parameter that indicates polarization sensitivity. The lower this polarization sensitivity, the closer are polarization and inequality concepts, in such a way that if $\gamma=0$ the polarization index is a scalar transformation of the Gini index (Gradín, 1999). For its part, $\lambda$ is the weight given to the measurement error that we normally consider $\lambda=1$. When $\lambda=0$ the extended polarization index of Esteban et al. (1999) would be similar to that of Esteban and Ray (1994). The difference between these two indices is that the former introduces the error term $\varepsilon=G(F)-G\left(\rho^{\prime}\right)$, with this being the lack of identification within groups when there exists some internal dispersion. The parameter $\rho^{\prime}$ minimizes the average income difference within groups. We take into account that the polarization measure is not independent of the number of groups and becomes more volatile the higher the number of groups (Esteban, 1996).

Table 1 shows the variation of inequality from 1994 to 2000 by using the Gini index. To that end, we use the initial income (the equivalent modified OECD household income before taxes and benefits), the gross income (the equivalent modified OECD household income after benefits) and the net income (the equivalent modified OECD household income after benefits and taxes). Additionally, the Tax and Benefits line of Table 1 shows the joint redistributive capacity of the welfare system, that is to say, including taxes and benefits. Finally, we compute the redistributive capacity of the system by considering only taxes.

\section{(Table 1)}

This Table reveals that there exists a higher inequality in both initial income and net income than that resulting from receiving benefits, that is to say, gross income. If we apply the tax system to this gross income distribution, inequality is reduced every year and, as a consequence, income is redistributed. The redistribution capacity of taxes is limited in 1998 and 1999, when the IRPF and general tax reforms of 1998 led to a reduction in tax progressivity, although this redistribution is compensated for by the redistributive capacity of public transfers. 
Table 2.a shows polarization measures where the parameter $\gamma$ is an index of sensitivity to polarization. ${ }^{3}$ As expected, polarization decreases when $\gamma$ is increased (Gradín, 1999). The higher the level of polarization, the less correlation there is with any of the inequality indices, and the polarization and inequality measures are closer to each other. Empirical evidence corroborates the interpretation that $\gamma$ is an index showing the point below which polarization and inequality differ.

\section{(Table 2.a)}

We observe in Table 2.b significant differences when considering two or six sub-populations in the sample. When we consider two sample groups, we take as a cut point the distribution's income average (Gradín, 2000). Esteban and Ray (1994) show that when we apply polarization measures to income distributions we are introducing biases when adopting alternative data aggregations at different intervals. We introduce these, as well as inequality measures, where such biases always have the same direction, that is to say, they underestimate real inequality.

\section{(Table 2.b)}

The literature illustrates the pattern of dissappearance of the middle class in the last decades, with a simultaneous increase in the inequality and polarization indicators which are unable to detect such an effect (Esteban and Ray, 1994; Esteban et al., 1999; Wolfson, 1994). In these circumstances, when talking about indices of inequality and polarization we are perhaps overlooking some of the evidence, specifically, what is happening to vulnerable groups in the population, such as the unemployed, the young, and women. In order to address this concern, measures at individual level, such as relative deprivation, are good complements to inequality and polarization indices, as they allow us to study each individual situation with respect to his/her reference group.

The concept of relative deprivation was first introduced by Runciman (1966). We would say that an individual with income $y_{i}$ feels deprived regarding another individual with income $y_{j}$ of their same reference group: $d_{i}(y)=\left(y_{j}-y_{i}\right)$ if $y_{i}<y_{j}$, and $d_{i}(y)=0$ in the rest of the cases (Yitzhaki, 1979; Hey and Lambert, 1980). The

\footnotetext{
${ }^{3}$ The polarization analysis is not implemented when we have a sample division of 8 or 24 groups, since, for this measure, a reduced number of groups of non-significant size would have less weight.
} 
relative deprivation function of an individual can be expressed in the following way: $d_{i}(y)=\frac{\sum_{j=i+1}^{n}\left(y_{j}-y_{i}\right)}{n}$ (D'Ambrosio and Frick, 2004).

Net income deprivation of individuals can be observed in Table 3 for each of the years when there are 6 reference groups. This is considerably lower than the annual average of gross income deprivation each year. As we have observed, the deprivation measure has the same trend as the polarization and inequality indices, and allows for a comparison between the individuals and those of their group, capturing the effect of the distribution of the group as being more or less equal. The inequality indices do not capture the relative effect of distribution within groups, only inequality in a particular population. The polarization concept is linked to those of deprivation and social exclusion, since they have as determinants the lack of identification with other members of society, and the aggregate alienation experienced with respect to those with lower income or satisfaction levels. Polarization and deprivation differ since deprivation is asymmetric in the sense that individuals are deprived in relation only to those who are better off in the sub-group, but in polarization, individuals compare themselves with respect to every one (Bossert et al., 2005). We can observe that the Esteban et al. (1999) polarization index is always higher than that of Esteban and Ray (1994), since the latter does not introduce the concept of lack of identification or heterogeneity within groups.

(Table 3)

\section{Data and empirical specification}

We use Spanish data from individuals with positive net personal income that comes from the eight waves of the European Community Household Panel-ECHP (19942001). ${ }^{4}$ We confirm that most individuals have a positive degree of deprivation in each period, measured in monetary terms, and only those in the higher income brackets suffer no deprivation at $\mathrm{all}^{5}$. We have selected those individuals who answer positively the

\footnotetext{
${ }^{4}$ In fact, we have seven waves, as the last year for each individual is lost, because in the ECHP income variables are related to the previous year. We measure income variables in real terms (base year is 1992) by dividing nominal income in $€$ by the consumer price index.

${ }^{5}$ When analyzing deprivation in monetary terms there is little value in considering situations in which deprivation is equal to 0 , since this occurs very rarely.
} 
question regarding economic satisfaction. Table 4 presents mean and standard deviations of both endogenous and explanatory variables used in the analysis.

(Table 4)

In order to model the income satisfaction, we propose the following specification:

$$
v_{i t}^{*}=\beta_{1}+\beta_{2} x_{i t}+\beta_{3} y_{i t}+\beta_{4} z_{i t}+\beta_{5} d_{i t}^{I}+u_{i t}
$$

where $v_{i t}^{*}$ is the latent subjective income satisfaction of the individual $i$ in period t. The subjective satisfaction variable, discrete and six-point ordinal, is the answer to the question "How satisfied are you with your present financial situation?" that takes values from 1 (not satisfied at all) to 6 (fully satisfied). This dependent variable is explained by a vector of individual characteristics $x_{i t}$, tax and benefit variables $y_{i t}$, and household characteristics $z_{i t}$, as well as by the individuals' relative deprivation $d_{i t}^{I}$. Since panel data allows us to control time invariant unobserved effects, we can express $u_{i t}=\alpha_{i}+e_{i t}$, with $e_{i t}$ being a white noise error term and $\alpha_{i}$ individuals' unobserved heterogeneity, assuming that $\alpha_{i}$ is random and independent of the explanatory variables. The observability rule for $v_{i t}^{*}$ is:

$$
v_{i t}=\left\{\begin{array}{ccc}
1 & \text { if } & v_{i t}^{*} \leq \kappa_{1} \\
2 & \text { if } & \kappa_{1}<v_{i t}^{*} \leq \kappa_{2} \\
\vdots & \vdots & \vdots \\
6 & \text { if } & v_{i t}^{*}>\kappa_{5}
\end{array}\right.
$$

where $\kappa_{1}, \ldots, \kappa_{5}$ are cut points which can be estimated jointly with the vector $\beta$. Since the responses to satisfaction are ordered responses, the conditional probabilities of each event can be expressed as:

$$
\begin{aligned}
& P\left(v_{i t}=j \mid x_{i t}, y_{i t}, z_{i t}, d_{i t}, \alpha_{i}\right)=\Phi\left(\kappa_{j+1}-\alpha_{i}-\beta_{1}-\beta_{2} x_{i t}-\beta_{3} y_{i t}-\beta_{4} z_{i t}-\beta_{5} d_{i t}\right)- \\
& \Phi\left(\kappa_{j}-\alpha_{i}-\beta_{1}-\beta_{2} x_{i t}-\beta_{3} y_{i t}-\beta_{4} z_{i t}-\beta_{5} d_{i t}\right)
\end{aligned}
$$

and we assume that the error term follows a standard normal distribution, so $\Phi(u)$ where $\Phi$ is the cumulative distribution function of the standard normal and (1) corresponds to a random effects ordered probit model. 
Satisfaction regarding income $v_{i t}$, and individual's deprivation $d_{i t}^{I}$ can be simultaneously determined in our model giving rise to an endogeneity problem. Endogeneity can have its origin in the economic model, but it could also be the result of feedback from the unobserved effects. An additional concern of $d_{i t}^{I}$ is its potential correlation with the error terms, arising from error measurement problems. It is necessary to instrument individual deprivation in order to overcome its endogeneity. We do this, when deprivation is expressed in monetary terms, by using the relative deprivation lagged one period. An alternative to treating the endogeneity problem when deprivation is expressed in satisfaction terms is to build an auxiliary regression as:

$d_{i t}^{I}=\delta_{1}+\delta_{2} x_{i t}+\delta_{3} y_{i t}+\delta_{4} z_{i t}+\varepsilon_{i t} \quad \mathrm{i}=1, \ldots, \mathrm{N} \quad \mathrm{t}=1, \ldots, 7 \quad I=S, N I, G I$

where $d_{i}^{I} \quad$ refers to SatisfactionDeprivation, NetIncomeDeprivation and GrossIncomeDeprivation, and $\delta_{1}, \delta_{2}, \delta_{3}$ and $\delta_{4}$ are parameters. As before, $x_{i t}$ are individual characteristics, $y_{i t}$ are taxes and benefit variables and $z_{i t}$ are household characteristics. The individual effects are random assuming that $\varepsilon_{i t}=\eta_{i}+w_{i t}$. Under the assumption of fixed effects, $\eta_{\mathrm{i}}$ represents the deviation with respect to $\delta_{1}$ for individual $i$, while $w_{i t}$ is an error term and we suppose they are independently distributed with zero mean and constant variance.

When analysing relative deprivation in monetary terms, the dependent variable is deprivation regarding those individuals of the reference group who are more satisfied or have a higher income level (SatisfactionDeprivation, NetIncomeDeprivation, GrossIncomeDeprivation). In this case, a continuous variable is built as the difference between the average income of those of the individual's reference group with higher income than the individual, and the individual's income. On the other hand, when relative deprivation is in satisfaction terms (SatisfactionDeprivation) it takes values that go from 0 (not deprived at all) to 5 (the most deprived an individual can be in satisfaction terms).

The explanatory variables that we will consider in this work include sociodemographic characteristics of the individual and some variables that indicate the individual situation in the labour market gathered in vector $x_{i t}$, as well as characteristics 
of the household $z_{i t}$. Further, we use some economic variables, such as public and private transfers received, and taxes paid $y_{i t}$.

Vector $x_{i t}$ of individual's characteristics is composed by individual's sociodemographic characteristics such as age (Age), age squared divided by 100 in order to capture the U-shaped effect $\left(\mathrm{Age}^{2} / 100\right)$, a gender variable (Male) and the individual's civil status (Married). We also include education levels reached by each of the individuals, distinguishing between primary, secondary and higher education (PrimEduc, SeconEduc, HighEduc), as well as a control for suffering any kind of physical or mental illness (Illness). The fact that this last could affect the ability to work, or travel to receive illness or unemployment benefits, would no doubt have an impact on an individual's economic satisfaction. The average age of individuals is 45 years old; $48 \%$ are male and 59\% are married. The proportion of individuals with primary education is about $66 \%$, with gender differences. Some $18 \%$ of individuals have reached secondary education, while a further $16 \%$ have obtained higher education levels.

Vector $z_{i t}$ is composed of characteristics of the household the individual belongs to, such as the number of family members (FamSize), which varies between 3 and 4, and whether individuals own a house or a flat (HouseOwnership). With respect to the individual's labour market characteristics, 9\% are unemployed (Unemployed), 8\% of individuals in the sample work in the public sector (PublicSector), 26\% are employed in the service or tertiary sector (ServiceSector), and 37\% are employed full-time (FullTime).

Finally, vector $y_{i t}$ is formed of economic variables such as the private and public transfers individuals receive and the taxes they pay. Our data reveal that $1.2 \%$ of individuals receive private transfers (Dummy PrivTransf), whose average is $2058.16 €$ net annual (PrivTransf). 26\% of those asked receive some kind of public benefit (Dummy PubTransf), that on average is $5352.11 €$ net per annum (PubTransf). $42 \%$ of those individuals in the sample pay taxes (Dummy Tax), the average payment being $3940.06 €$ (Taxes). Additionally, we observe that $19 \%$ of individuals suffer some type of physical or mental illness, although only $4 \%$ receive any illness or disability benefit (Dummy IllnessTransf), whose average is $4851.51 €$ a year (IllnessTransf). $4 \%$ of the individuals sampled receive unemployment benefits (Dummy UnempTransf), with an 
individual's average being $2959.06 €$ per annum (UnempTransf). 16\% of individuals receive some type of retirement or widowhood benefit (Dummy RetWidTransf), whose average is $6594.39 €$ net per annum (RetWidTransf). $12 \%$ of the sample receive retirement benefits, with an average of $7025 €$, and $5 \%$ of the sample receive widowhood transfers averaging $4530.70 €$ per annum. Finally, $1 \%$ of individuals receive family protection benefits (Dummy MatTransf) (maternity benefits) averaging $1220.01 €$ net per annum (MatTransf).

In the following Table we summarise the instruments associated with every variable, as well as where they appear in the corresponding empirical results which will be described in the next Section.

\begin{tabular}{|c|c|c|}
\hline Variable & Instrument & Results \\
\hline Satisfaction Deprivation & Satisfaction Deprivation predicted & $\begin{array}{l}\text { Columns } 1,2 \text { and } 3 \text { of } \\
\text { Tables 5.a and 5.b }\end{array}$ \\
\hline Income Deprivation & Income Deprivation lagged a period & $\begin{array}{l}\text { Columns } 4-9 \text { of Tables 5.a } \\
\text { and 5.b }\end{array}$ \\
\hline Taxes Dummy & Probability of the individual paying taxes & $\begin{array}{l}\text { Table 5.a and 5.b, 6, 7.a, 7.b } \\
\text { and 7.c }\end{array}$ \\
\hline Dummy Public Transfers & $\begin{array}{l}\text { Proportion of individuals each year in each of the cohorts in our } \\
\text { dataset that perceive public transfers }\end{array}$ & Table 5.b \\
\hline Dummy Unemployment Benefits & $\begin{array}{l}\text { Proportion of individuals each year in each of the cohorts } \\
\text { receiving those benefits with data drawn from Encuesta de } \\
\text { Población Activa }\end{array}$ & Tables 7.a, 7.b and 7.c \\
\hline Dummy Retirement Benefits & $\begin{array}{l}\text { Proportion of individuals each year in each of the cohorts } \\
\text { receiving those benefits with data drawn from Instituto } \\
\text { Nacional de la Seguridad Social }\end{array}$ & Table 7.c \\
\hline Dummy Widowhood Benefits & $\begin{array}{l}\text { Proportion of individuals each year in each of the cohorts } \\
\text { receiving those benefits with data drawn from Instituto } \\
\text { Nacional de la Seguridad Social }\end{array}$ & Table 7.c \\
\hline Dummy Maternity Benefits & $\begin{array}{l}\text { Proportion of individuals each year in each of the cohorts } \\
\text { receiving those benefits with data drawn from Encuesta de } \\
\text { Fecundidad } 1998\end{array}$ & $\begin{array}{l}\text { Table } 7 . b \text { and columns } 2,4 \\
\text { and } 6 \text { of Table } 7 . c\end{array}$ \\
\hline $\begin{array}{l}\text { Amount of the different public transfers } \\
\text { and taxes }\end{array}$ & $\begin{array}{l}\text { Taxe and unemployment, retirement, widowhood, maternity, } \\
\text { illness and public benefits }\end{array}$ & Tables 9.a, 9.b and 9.c \\
\hline
\end{tabular}

\section{Empirical results}

The estimation procedure follows these steps. First, we estimate the deprivation equation (4), in both satisfaction and monetary terms, considering the aggregated data, a fixed effects and a random effects estimation. ${ }^{6}$ Then, we use the estimated values for instrumenting $d_{i}^{I}$ in the economic satisfaction equation (1) considering the aggregated data. Since the coefficients of the deprivation equation are also informative, although

\footnotetext{
${ }^{6}$ As is well known, the difference between the two panel estimations lies in the fact that, while in the case of fixed effects the $\eta$ 's are considered as fixed values (a dummy for each individual), in the specification of random effects the specific aspects of each spouse are taken as independent random variables.
} 
they correspond to a reduced form, we structure this section first describing the results of the determinants of individuals' relative deprivation and then showing the results regarding satisfaction with income.

\subsection{Relative deprivation, in both satisfaction and monetary terms.}

In Tables 5 and 6 we observe the determinants of income and satisfaction deprivation. In every case, we have implemented a pooled, a fixed effects and a random effects estimation, with the pooled or panel being selected by an LM test (Breusch-Pagan) and the choice between the fixed and random effects being made by using a Hausman test. Both tests allow us to confirm, in every case, that the panel estimation of the unobserved individual effects is preferable to the pooled estimation, and also that fixed effects are more accurate than random effects. This is so because the type of sociodemographic variables that we introduce in our analysis are potentially correlated with the unobserved effects.

Table 5 shows how individual deprivation, in both satisfaction and monetary terms, is affected, whether or not the individual is receiving private or public transfers and paying taxes. Private transfers affect deprivation in a positive way, while the effect of public transfers is negative. This could mean that an individual receives greater private transfers from friends or relatives because he is very deprived. It points towards a stigma effect, because the number of individuals who receive private transfers is much smaller compared to those who obtain benefits from the government. If the individual receives public transfers, he/she is going to feel less deprived, in such a way that the welfare system is behaving appropriately in reducing the deprivation of individuals. Moreover, taxes have a negative effect, that is to say, reducing net income deprivation. Chakravarty and Moyes (2003) studied the effect of taxation on the amount of deprivation felt in society as a whole, and they found that the more progressive the system, the higher the social deprivation. We observe that those who pay taxes are less deprived in relative terms in their reference group, with this confirming the redistributive effect of the tax system. Finally, the source of income negatively affects relative deprivation in gross and net monetary terms, when we consider samples based on 6 and 8 cohorts.

(Table 5) 
Regarding socio-demographic variables, we observe that age positively influences deprivation in monetary terms. However, age squared affects such deprivation negatively, as opposed to what happens regarding satisfaction deprivation. The fact that the individual is married reduces his/her satisfaction deprivation, in such a way that the family here could be considered as an insurance mechanism that protects individuals against adverse shocks. When the individual reaches secondary and higher education levels, deprivation increases, since these individuals consider that they are less deprived, or more satisfied, or better-paid as a consequence of their higher education level. The fact that the individual is ill leads to a greater degree of satisfaction deprivation, but to a lesser degree of income deprivation, since the individual receives an illness benefit. The individual feels more deprived the larger the household he/she belongs to. Although it is well known that having at least one child in the household provides satisfaction, satisfaction deprivation increases as the number of children increases.

Regarding the situation in the labour market, we observe that when the individual is unemployed, the more deprived he/she feels in satisfaction terms, arising from a perception of a higher deprivation in satisfaction and net monetary terms. This effect should not only be seen as a loss of income, but also as a reduction of happiness, resulting from a decline in self-esteem, the loss of social relationships established at the workplace, and the loss of the sense of contributing to society in a wider sense. The same result has been found in Waters and Moore (2001), who determined that the unemployed suffer from economic deprivation, and studied its linkage to psychological problems. When the individual works in the public sector, deprivation in satisfaction terms is lessened; on the other hand, in the service sector, deprivation in satisfaction terms is reduced, but increased in net monetary terms. Having a full-time contract is perceived to be the most important element in reducing an individual's sense of deprivation.

Tables 6.a, 6.b and 6.c present relative deprivation, in both satisfaction and income terms, distinguished by the receipt of public transfers, including unemployment, retirement, widowhood, maternity, illness and scholarships. The significance of the variables is similar to that in Table 5 . For the sake of brevity, we only describe the results specifically coming from the different public transfers. Unemployment, retirement, widowhood and illness transfers have a negative effect on satisfaction 
deprivation, as well as on income in both gross and net deprivation terms. This negative effect indicates that the welfare system is achieving its goals in reducing the deprivation of the beneficiaries. However, maternity transfers positively influence income deprivation and, given that income is not controlled for when analysing the effect of transfers on deprivation, an income effect could underly this unexpected result.

In these Tables we found the same results as when unemployment benefits and tax dummies were not instrumented. Since transfers form part of the welfare system, and their aim is to improve the welfare of the individuals, transfers can be endogenous in our estimated models. In these circumstances, we are going to instrument these transfers, with the following results.

The unemployment benefit dummy is instrumented by the proportion of unemployed people that year in the corresponding cohort who receive such a benefit, with data drawn from the Spanish Labour Force Survey (Tables 6.a, 6.b and 6.c). Thus, we find that those receiving unemployment benefits are less deprived.

Maternity benefits are instrumented by the proportion of individuals who give birth, or expect to give birth, in the corresponding cohort in that year, and thus receive such a benefit. We take data drawn from the Spanish Fertility Survey (Table 6.b and columns 2, 4 and 6 in Table 6.c). In implementing this analysis we lose another wave since the fertility survey only covers the period up to 1999. For those who receive maternity benefits, satisfaction deprivation for the 6 cohorts case is reduced, but deprivation in monetary terms increases, as we saw in our previous analysis where the dummy for maternity benefits was potentially endogenous (Table 6.a).

In Table 6.c we have the same analysis as in Tables 6.a and 6.b, without and with instrumenting maternity benefits, respectively, for the 8 reference group case, where we instrument whether the individual receives or does not receive retirement and widowhood benefits, by using data drawn from the National Institute of Social Security. We find that individual deprivation is reduced when receiving unemployment, retirement or widowhood benefits. The effect of instrumenting taxes on net income deprivation, when public transfers are not considered individually, but are aggregated, is negative. $^{7}$

\footnotetext{
7 We instrument taxes by predicting the likelihood that individuals will pay taxes (Gruber and Mullainathan, 2005).
} 
(Tables 6.a, 6.b and 6.c)

In Tables 7.a, 7.b and 7.c, we specifically study the effect that the amount of benefits received has on satisfaction deprivation. We select those individuals who receive private and public transfers, and pay taxes in the first three columns respectively. Moreover, the different public transfers are individual, but not aggregated in the six following columns: unemployment, retirement or widowhood, maternity, illness, retirement alone, and finally, widowhood alone.

(Tables 7.a, 7.b and 7.c)

We confirm the U-shaped effect of unemployment on deprivation only in the case of 8 cohorts, and of public transfers, retirement or widowhood, and only retirement benefits, for the three different cases, 6,8 and 24 cohorts. The higher the amount of maternity transfers, the lower the deprivation in satisfaction terms, as happens with illness benefits when 8 and 24 groups are considered, and with unemployment benefits when 6 and 24 groups are considered. The higher the quantity received, the less deprived individuals are. Once the threshold is reached, the higher the amount received, the less deprived is the individual, but at a lower rate. We use, as instruments of the amounts of benefits received in such transfers, this variable in both a linear and a squared way lagged one period. Moreover, the variable employed to instrument taxes paid is the amount of taxes paid lagged one period. We find a similar result when we consider large and small numbers of reference groups. The more taxes individuals pay, the less deprived they feel, since they are wealthier compared to those of their reference group.

\subsection{Income satisfaction}

We report in Table 8 the individual's income satisfaction, with each column being the result of a random effects ordered probit. The first three columns present the effect of satisfaction deprivation, and the remaining six columns describe the effect of income relative deprivation on satisfaction.

(Table 8)

The more deprived an individual, in terms of the satisfaction of those individuals of the reference group, the less economically satisfied he/she is. ${ }^{8}$ We use the estimated

\footnotetext{
${ }^{8}$ A similar result was found by D’Ambrosio and Frick (2004).
} 
value obtained in the auxiliary regression to instrument satisfaction deprivation, with this instrument predicting correctly $100 \%$ of the cases. We calculate robust standard errors to account for the estimation of the auxiliary regression.

We find a clear positive effect, but at a decreasing rate, of income deprivation on income satisfaction, after including equivalent household income in absolute terms. This threshold is lower for post-taxes and benefits deprivation, than for pre-taxes deprivation. To instrument income deprivation, for both the linear and squared variables, we employ the variable lagged one period. After controlling for both relative and absolute income, we observe a clear and significant effect of relative income, in such a way that we are able to accept the relative income hypothesis. Moreover, net equivalent household income affects each individual's satisfaction positively ${ }^{9}$

When we study deprivation in monetary terms, and introduce third and fourth order polynomials, we find an unexpected significance. This shows that deprivation should be considered as a multidimensional concept and different deprivation dimensions, such as inability to satisfy the maintenance needs and functions, goods, facilities and opportunities in the household environment, health, activity status, educational level, social integration and leisure, should be aggregated (Chakravarty and D’Ambrosio, 2003; Bossert et al., 2005; Pérez-Mayo, 2005). In this way, satisfaction deprivation is a more accurate measure as it includes the aforementioned dimensions (household environment, health, activity status, educational level, ...), since, when individuals report their deprivation, they are considering such dimensions.

We introduce in the specifications the income variance of each group to determine whether the satisfaction of individuals is affected, not only by income levels, but also by income inequality within each of the groups. Thus, the higher the variance within a group, the less economically satisfied are the members of that group, with this being observed for 6 and 8 cohorts when gross income terms are considered. Empirical evidence suggests that, when there are many reference groups in very unequal societies, those societies tend to be more stable than when the number of groups is smaller, since deprivation in the former case is not very high (Yitzhaki, 1982).

\footnotetext{
${ }^{9}$ We compute net equivalent household income using the modified OECD equivalence scale. This scale assigns value 1 to a single-person household (reference) and it gives weight of 0.5 to the rest of the adult member and 0.3 to children.
} 
With income variation within groups we attempt to show that income satisfaction depends, not only on the deprivation felt regarding those members of the group who declare a higher satisfaction or income, but also on how income is distributed within each of the reference groups.

We observe that the older the individual, the less satisfied he feels with his economic situation, with this applying up to the age of 35-36 when considering both post-taxes and benefits, and when taking into account income before taxes. When we introduce the variable in squared terms, we expect to observe a U-shaped profile indicating increased satisfaction, as in Clark et al. (1996). We also confirm the fact that married status affects satisfaction positively when deprivation is introduced in monetary terms. We also observe that the satisfaction of the individual who reaches secondary and higher education levels increases. The fact that the individual suffers an illness has a negative effect on economic satisfaction. Regarding the household variables, we find that household size has a negative effect when introducing deprivation variables in monetary terms. On the other hand, when the household owns a house or a flat, individual satisfaction in this household is increased compared to those who are rentpaying tenants. The more children under 16 are in the household, the less income satisfaction the individual reports.

When we consider variables related to the individual labour situation, we confirm the fact that unemployed individuals are affected strongly and negatively in terms of satisfaction (Ahn et al., 2004; Layard, 2005). On the other hand, the fact of being employed in the public sector, as well as having a full-time contract, has a very positive effect on individual subjective satisfaction, especially when we introduce deprivation variables in monetary terms.

Regarding economic variables, we observe that the source of income is a significant variable when satisfaction deprivation is considered The fact that the individual receives private transfers has a negative effect on satisfaction. When the individual receives public transfers, satisfaction is also negatively affected. When we instrument the dummy variable of individuals receiving public transfers by using the proportion of individuals that year in the corresponding cohort who receive such transfers, the effect of the dummy variable indicating receiving public transfers is positive, in such a way that, specifically for 8 and 24 cohorts, those individuals are more income satisfied. The fact that the individual pays taxes has a negative effect on his 
satisfaction. When we instrument to account for the potential endogeneity of the dummy variable that indicates whether the individual pays taxes or not, by using the predicting variable, the likelihood of the individual paying taxes reduces satisfaction, with this seeming to confirm the anticipated endogeneity.

To sum up, the results of the random effects ordered probit are the same when we consider relative income deprivation in monetary terms, regardless of the number of cohorts in the sample. We confirm that taking into account 6, 8 or 24 reference groups in the sample does not change our results, thus we can conclude that they are robust for different reference group definitions.

Finally, we carry out a simulation exercise that allows us to identify the economic policies that should be applied, and we observe to what extent these transfers should increase if we expect individuals to reach a satisfaction level of at least 4 points on a 6-point scale. Taking into account the satisfaction that individuals receiving public, retirement and unemployment benefits declare, and the effect an increase in those transfers would have, we have developed a simulation exercise in which we select those who receive transfers and do not reach a desired level of satisfaction. We are going to analyze, caeteris paribus, to what extent policy-makers should increase those transfers to allow individuals to reach a satisfaction level of at least 4 .

A priori, we could predict how perception of transfers or tax payments would affect the economic satisfaction an individual declares, and to what extent governments should increase transfers to those who are eligible, in order to reach a given level of satisfaction. Our recommendation would be that public transfers, specifically unemployment benefits, should be double those that already exist. However, retirement benefits should have been increased by 75\%, with a decreasing trend from 1995 and higher values in the first two years of our sample period. The fact that the three kinds of benefits, aggregated public transfers, unemployment and retirement, should be increased in the later years, 1998, 1999 and 2000, by less than 100\%, led us to the following result. Since the amounts received are higher in those years, so the average level of satisfaction increases over the whole period. Thus, a lesser percentage increase would be necessary in order to reach an overall satisfaction level of 4 points.

With this exercise we establish two strong assumptions. One consists of considering the enhanced satisfaction of individuals simply by increasing the amount of 
those transfers received. The other would be a budget increase in order to apply these policy suggestions, where in some years and for some groups, the expenditure should be doubled. We believe this implementation would be justified because society is concerned with individual satisfaction and how policies affect individual well-being, since the first aim of government is to increase the welfare of individuals in a society. This highest good would generate, by itself, positive externalities that would compensate for other negative forces in society.

Tables 9a, 9b and 9c show by how much different benefits should be augmented in order to increase satisfaction by 1 point on the scale (Boes and Winkelmann, 2004). ${ }^{10}$ Unemployment and widowhood benefits need to be increased in a higher proportion than retirement, illness and scholarship benefits, in order to achieve this increase.

From this analysis we find that to increase individual satisfaction from 1 point to 2, or from 2 points to 3 , is different than from 3 points to 4 and from 4 points to 5 . The higher the individual satisfaction level, the higher the amount of transfer needed to increase satisfaction levels by one point. Specifically, the amount needed to increase satisfaction by 1 point would be similar when the satisfaction level is either 1 or 2 . But, as utility is concave, a higher amount of transfers would be needed in order to increase satisfaction by 1 point when this individual satisfaction level is around 3 points, and an even higher amount would be needed to increase satisfaction by 1 point when individual satisfaction level is around 4 points.

(Tables 9a, 9b and 9c)

\section{Conclusions}

The main objective of this paper was to identify the determinants of both income satisfaction and relative deprivation, in monetary and satisfaction terms, by using data from the eight available waves of the Spanish section of the European Community Household Panel (1994-2001).

Our results suggest that the more unequal the income distribution within a group, the less income-satisfied is the individual. Therefore, equality should be one of the main

${ }^{10}$ The expression is $\left|\frac{\kappa_{s+1}-\kappa_{s}}{\hat{\beta}_{i}}\right|$, where $i$ corresponds to different kinds of transfer. 
objectives of government policies in order to increase individual well-being. Moreover, being unemployed is one of the main determinants of deprivation, and we have shown that public benefits reduce individual deprivation. When we observe the amount of public transfers received, deprivation is reduced up to a certain threshold, beyond which it continues to decline but at a lower rate.

Policies aimed at reducing deprivation should be implemented, since if deprivation persists or increases over time, there is a risk for certain vulnerable groups, such as chidren, the unemployed, and the elderly to become socially excluded (D’ambrosio and Gradín, 2001; Cantó and Mercader, 1998). Finally, we implemented an analysis in order to determine to what extent governments should have increased transfers to those eligible individuals, in order to reach a satisfaction level of at least 4 . Our recommendation would be that public transfers, specifically, unemployment benefits, should be double those that already exist. However, retirement benefits should be increased by $75 \%$.

\section{Acknowledgements}

This research was conducted while María Navarro was Visiting Fellow at the Fundación de Estudios de Economía Aplicada (FEDEA). I am very grateful for the hospitality and facilities provided. I am indebted to comments from participants at the XXXI Simposio de Análisis Económico and in a seminar at FEDEA and specially to Namkee Ahn and Juan Ramón García. The authors would also like to express their thanks for the financial support provided by projects SEJ2005-08793-C04-04, SEJ2005-06522/ECON and the Aragon Government grant B168/2003. The usual disclaimer applies. 


\section{References}

Ahn, N., García, J. R., and Jimeno, J. F. (2004). "Well-being consequences of unemployment in Europe”, WP FEDEA 2004-11.

Atkinson, A. (1970). “On the measurement of inequality”, Journal of Economic Theory, 2, 244-263.

Barret, C. B., and Esteban, J. (2005). "Social groups and economic inequality”, Journal of Economic Inequality, 3, 187-191.

Boes, S., and Winkelmann, R. (2004). "Income and happiness: new results from generalized threshold and sequential models”, IZA DP 1175.

Bonke, J., and Browning, M. (2003). "The distribution of well-being and income within the household”, WP 2003-01 Centre for Applied Microeconometrics, University of Copenhagen.

Bossert, W., D’Ambrosio, C and Peragine, V. (2005). "Deprivation and social exclusion”, CHILD WP 03/2005 Centre for Household, Income, Labour and Demographic Economics.

Buchanan, James M. (1965). "An economic theory of clubs", Economica, 32, 1-14.

Burkhauser, R.V., J.R. Frick, and Schwarze, J. (1997). “A comparison of alternative measures of economic well-being for Germany and the United States”, Review of Income and Wealth, 43, 153-171.

Cantó, O and Mercader-Prats, M. (1998). “Child poverty in Spain: what can be said?” Innocenti Occasional Papers, Economic and Social Policy Series, no. 66. Florence: UNICEF International Child Development Centre.

Chakravarty, S. R., and Chakraborty, A. B. (1984). “On indices of relative deprivation”, Economic Letters, 14, 283-287.

Chakravarty, S. R., and D’Ambrosio, C. (2003). “The measurement of social exclusion”, Discussion Paper 364, DIW Berlin.

Chakravarty, S. R., and Moyes, P. (2003). "Individual welfare, social deprivation and income taxation.” Economic Theory, 21, 843-869.

Chakravarty, S. R., and Mukherjee, D. (1999). "Measures of deprivation and their meaning in terms of social satisfaction”, Theory and Decission, 47, 89-100. 
Clark, A., Diener, E., Lucas, R., and Georgellis, Y. (2004), "Unemployment alters the set-point for life satisfaction”, Psychological Science, 15 , 8-13.

D’Ambrosio, C and Gradín, C (2001). "Polarización intergeneracional y exclusión social de los niños en España e Italia”, in Labeaga, JM and M. Mercader-Prats (eds.) Desigualdad, Redistribución y Bienestar: Una Aproximación a partir de la Microsimulación de Reformas Fiscales. Instituto de Estudios Fiscales, Madrid.

D’Ambrosio, C., and Frick, J.R. (2004). "Subjective well-being and relative deprivation: an empirical link”, IZA DP 1351.

Dasgupta, P.S., Sen, A.M. and Starret, D.A. (1973). "Notes on the measurement of inequality", Journal of Economic Theory, 6, 180-187.

Diener, E., Lucas, R. (1999). “Personality and subjective well-being”, In Kahneman, D., Diener, E. and Schwarz, N. (eds.), Well-Being: Foundations of Hedonic Psychology: Scientific Perspectives on Enjoyment and Suffering. Russell Sage Foundations.

Duesenberry, J. S. (1949). Income, Saving and the Theory of Consumer Behaviour, Cambridge, Harvard University Press.

Easterlin, R. A. (2002). Happiness in Economics, Chaltenham (UK) and Northampton (Mass.), Edward Elgar.

Esteban, J M. (1996). “Desigualdad y polarización. Una aplicación a la distribución interprovincial de la renta en España”, Revista de Economía Aplicada, 4, 5-26.

Esteban, J. M and Ray, D. (1994). "On the measurement of polarization", Econometrica, 62, 819-851.

Esteban, J. M. Gradín, C and Ray, D. (1999). “ Extensions of a measure of polarization with an application to the income distributions of five OECD countries”, Documentos de Trabajo, Instituto de Estudios Económicos de Galicia-P. Barrié de la Maza, 24/1999.

Ferrer-i-Carbonell, A. and Van Praag, B. (2003). "Income satisfaction inequality and its causes”, Journal of Economic Inequality, 1, 107-127.

Frey, B. S., and Stutzer, A. (2002). "What can economists learn from happiness research?”, Journal of Economic Literature, 40, 402-435. 
Gradín, C. (1999). “Polarization and inequality in Spain, 1973-1991”, DT 9907 Departamento de Economía Aplicada, Universidad de Vigo.

Gradín, C. (2000). "Polarization by subpopulations in Spain, 1973-91”, Review of Income and Wealth, 46, 4, 457-474.

Gruber, J. H., and Mullainathan, S. (2005). “Do cigarette taxes make smokers happier?” Advances in Economic Analysis and Policy, 5, 1, 1-43.

Hamermesh, D. S. (2004). “Subjective outcomes in economics”, NBER Working Papers 10361.

Hey, J. D. and Lambert, P. J (1980). "Relative deprivation and the Gini coefficient: comment”, Quarterly Journal of Economics, 94, 567-573.

Kahneman, D., Diener, E. and Schwarz, N. (1999) Well-Being: Foundations of Hedonic Psychology: Scientific Perspectives on Enjoyment and Suffering. Russell Sage Foundations.

Kakwani, N. (1984). "The relative deprivation curve and its applications”, Journal of Business and Economic Statistics, 4, 384-94.

Lambert, P. J. (1985). “Social welfare and the Gini coefficient revisited”, Mathematical Social Sciences, 9, 19-26.

Layard, R. (2005). Happiness. Lessons From a New Science. New York: Penguin.

Oliver Alonso, J; Ramos, X and Raymond Bara, J L. (2002). "La desigualdad en la distribución de la renta en la UE a mediados de los noventa: evidencia del Panel de Hogares Europeo”, Papeles de Economía Española, 91, 129-50.

Osberg L. y Sharpe, A. (2002). “An index of economic well-being for selected OECD countries”, Review of Income y Wealth, 48, 291-316.

Oswald, A., Clark, A., and P. Warr. (1996). “Is job satisfaction U-shaped in age?”, Journal of Occupational and Organizational Psychology, 69, 57-81.

Oswald, A. (1997). “Happiness and economic performance”, Economic Journal, 107, 1815-1831.

Paul, S. (1991). “An index of relative deprivation.” Economics Letters, 36, 337-341.

Pérez-Mayo, J. (2005). “Identifying deprivation profiles in Spain: a new approach”, Applied Economics, 37, 943-955. 
Podder, N. (1996). "Relative reprivation, envy and economic inequality.” Kyklos, 49, 3, 353-376.

Runciman, W. G. (1966). Relative Deprivation and Social Justice. Routledge and Kegan Paul, London.

Sen, A. (1976). “Poverty: an ordinal approach to measurement”, Econometrica, 44, 21931.

Schwarze, J. (2003). "Using panel data on income satisfaction to estimate equivalence scale elasticity”, Review of Income and Wealth, 49, 359-372.

Takayama, N. (1979) "Poverty, income inequality, and their measures: Professor Sen’s axiomatic approach reconsidered”, Econometrica, 47, 747-760.

Waters, L. E., and Moore, K. A. (2001). “Coping with economic deprivation during unemployment”, Journal of Economic Psychology, 22, 461-482.

Yitzhaki, S. (1979). "Relative deprivation and the Gini coefficient”, Quarterly Journal of Economics, 93, 321-324.

Yitzhaki, S. (1982). "Relative deprivation and economic welfare”, European Economic Review, 17, 99-113. 
Table 1. Inequality (Gini) evidence (6, 8 and 24 groups)

\begin{tabular}{|c|c|c|c|c|c|c|c|c|c|c|c|c|c|c|c|c|c|c|c|c|c|c|c|c|c|}
\hline 6 Groups & TOTAL & G1 & G2 & G3 & G4 & G5 & G6 & G7 & G8 & G9 & G10 & G11 & G12 & G13 & G14 & G15 & G16 & G17 & G18 & G19 & G20 & G21 & G22 & G23 & G24 \\
\hline Initial Income & $-3,32$ & $-3,10$ & 2,06 & $-9,25$ & $-7,22$ & $-8,01$ & $-0,44$ & & & & & & & & & & & & & & & & & & \\
\hline Gross Income & $-5,19$ & $-2,25$ & $-3,81$ & $-16,39$ & $-9,13$ & $-9,49$ & $-6,62$ & & & & & & & & & & & & & & & & & & \\
\hline Net Income & $-3,65$ & $-1,36$ & $-2,69$ & $-11,47$ & $-5,14$ & $-6,84$ & $-5,75$ & & & & & & & & & & & & & & & & & & \\
\hline Tax and Ben & 1,08 & $-5,88$ & 15,25 & 9,36 & $-6,43$ & $-4,23$ & 17,73 & & & & & & & & & & & & & & & & & & \\
\hline Taxes & $-11,05$ & $-16,44$ & $-20,13$ & $-30,73$ & $-16,65$ & $-16,93$ & $-3,53$ & & & & & & & & & & & & & & & & & & \\
\hline 8 Groups & & G1 & G2 & G3 & G4 & G5 & G6 & G7 & G8 & G9 & G10 & G11 & G12 & G13 & G14 & G15 & G16 & G17 & G18 & G19 & G20 & G21 & G22 & G23 & G24 \\
\hline Initial Income & & $-8,63$ & $-6,67$ & 12,73 & $-4,54$ & $-21,33$ & 1,92 & 2,94 & 3,68 & & & & & & & & & & & & & & & & \\
\hline Gross Income & & 3,59 & 8,89 & $-8,37$ & $-16,95$ & $-5,12$ & $-8,73$ & $-4,27$ & $-4,35$ & & & & & & & & & & & & & & & & \\
\hline Net Income & & 0,94 & $-1,82$ & $-1,17$ & $-16,43$ & $-9,37$ & $-1,88$ & 13,71 & $-1,00$ & & & & & & & & & & & & & & & & \\
\hline Tax and Ben & & $-29,05$ & $-20,24$ & 66,77 & 59,92 & $-37,48$ & 10,00 & $-16,90$ & 8,44 & & & & & & & & & & & & & & & & \\
\hline Taxes & & 22,62 & 126,75 & $-39,55$ & $-4,71$ & 30,56 & $-44,76$ & $-106,79$ & $-25,29$ & & & & & & & & & & & & & & & & \\
\hline 24 Groups & & G1 & G2 & G3 & G4 & G5 & G6 & G7 & G8 & G9 & G10 & G11 & G12 & G13 & G14 & G15 & G16 & G17 & G18 & G19 & G20 & G21 & G22 & G23 & G24 \\
\hline Initial Income & & 10,86 & 5,97 & $-13,64$ & $-15,05$ & $-11,22$ & $-10,91$ & $-7,22$ & $-17,09$ & 12,44 & $-9,23$ & $-17,22$ & $-38,65$ & $-5,32$ & 2,88 & $-18,80$ & $-8,94$ & $-5,03$ & $-5,73$ & 2,74 & 4,29 & 10,06 & 86,87 & 15,27 & $-2,22$ \\
\hline Gross Income & & 0,33 & 3,44 & $-5,66$ & $-15,72$ & $-10,93$ & $-7,83$ & $-7,87$ & $-12,65$ & $-14,04$ & 30,18 & $-28,04$ & 1,37 & $-15,27$ & 2,08 & 22,22 & $-3,26$ & $-15,91$ & $-17,83$ & 1,36 & $-4,75$ & $-10,48$ & $-16,32$ & $-32,23$ & $-10,19$ \\
\hline Net Income & & 8,25 & $-0,35$ & $-10,49$ & $-7,28$ & $-1,85$ & $-10,79$ & $-6,23$ & $-10,13$ & $-19,55$ & $-2,20$ & $-22,14$ & $-39,44$ & 0,33 & $-4,10$ & $-12,69$ & 11,03 & $-16,02$ & 11,07 & 4,63 & $-1,09$ & 1,05 & 26,34 & $-20,95$ & $-33,33$ \\
\hline Tax and Ben & & 10,26 & 46,11 & $-10,35$ & $-31,19$ & $-42,57$ & $-0,37$ & $-5,70$ & $-39,96$ & 194,51 & $-17,98$ & 18,63 & 3,07 & $-15,58$ & 18,32 & $-19,76$ & $-45,33$ & 57,20 & $-41,62$ & $-3,10$ & 9,42 & 16,01 & 108,87 & 91,01 & 88,98 \\
\hline Taxes & & $-1116,67$ & $-36,83$ & 30,36 & $-63,39$ & $-37,91$ & 16,26 & & $-113,83$ & 66,81 & 4568,49 & $-15,68$ & $-403,14$ & $-152,78$ & 50,27 & 720,24 & $-33,27$ & 0,91 & $-85,71$ & $-26,28$ & $-28,50$ & $-49,38$ & $-77,87$ & $-41,18$ & 249,01 \\
\hline
\end{tabular}

6 GROUPS: G1: Primary educated male; G2: Primary educated female; G3: Secondary educated male; G4: Secondary educated female; G5: Higher educated male; G6: Higher educated female

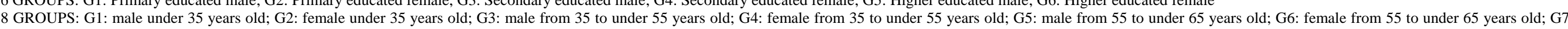
male from 65 years old; G8: female from 65 years old

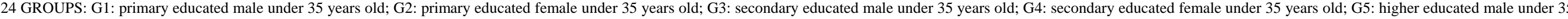

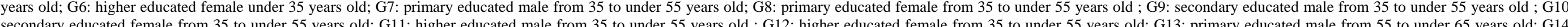

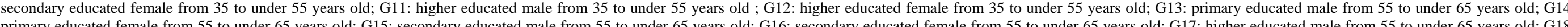

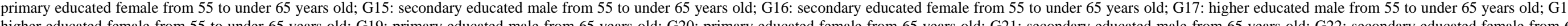

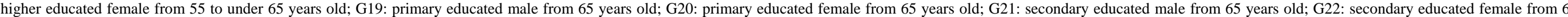

years old; G23: higher educated male from 65 years old; G24: higher educated female from 65 years old. 
Figure 1. Gini index

Gini Index

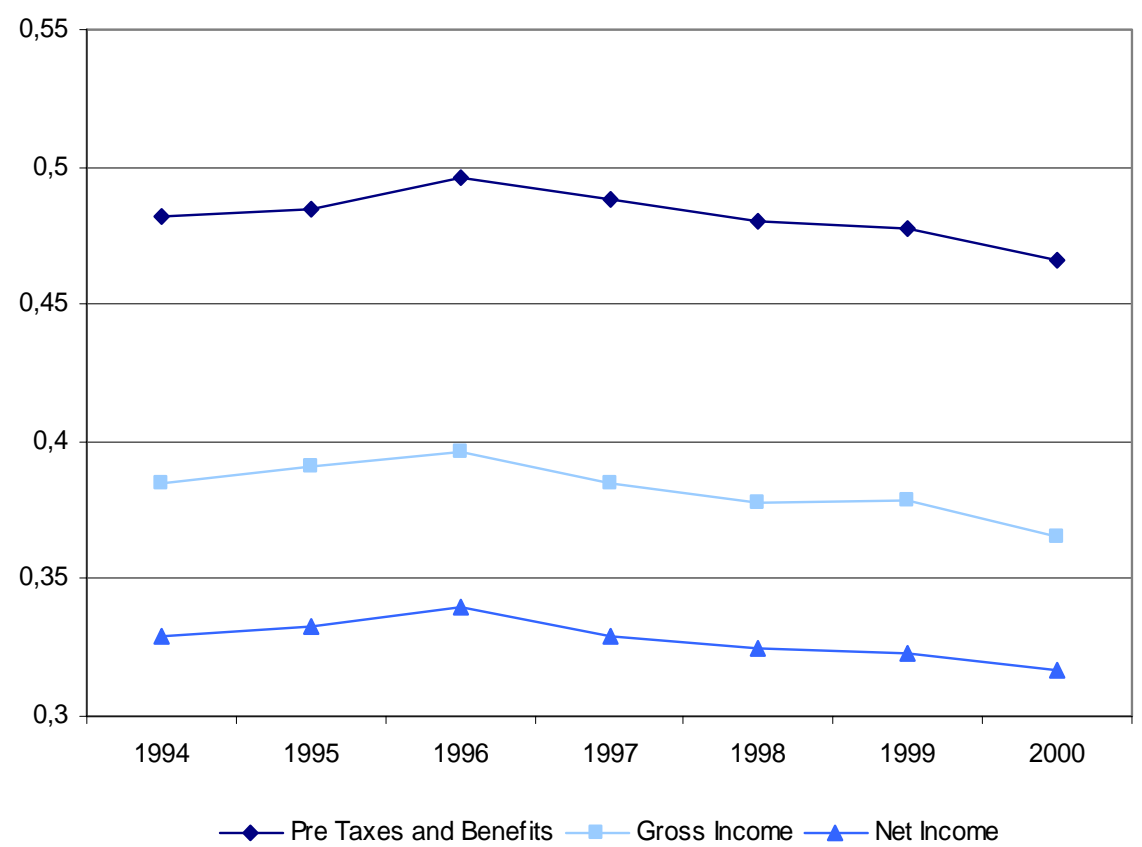

Figure 2. Income redistribution

Income Redistribution

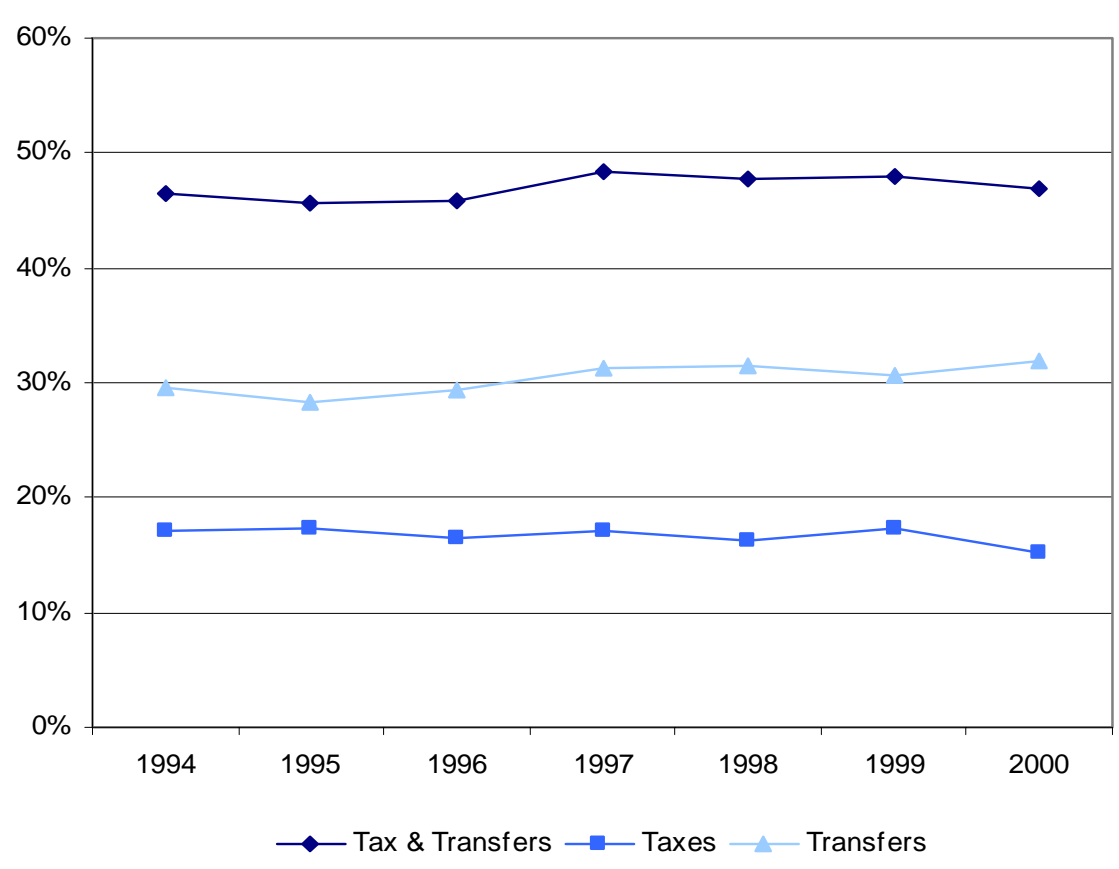


Table 2.a Polarization evidence (6 groups)

\begin{tabular}{lccccccc}
\hline & \multicolumn{2}{c}{ POLARIZATION ER 1994 } & Polariz error & \multicolumn{2}{c}{ POLARIZATION EGR 1999 } \\
& $\gamma=1$ & $\gamma=1$ & $\gamma=1$ & $\varepsilon$ & $\lambda=1$ & $\lambda=0.5$ & $\lambda=0.5$ \\
\hline 1994 & 0.0980105 & 0.0674842 & 0.0473004 & 0.087 & 0.0110105 & 0.0239842 & 0.0038004 \\
1995 & 0.0978569 & 0.0670686 & 0.0468021 & 0.083 & 0.0148569 & 0.0255686 & 0.0053021 \\
1996 & 0.0974573 & 0.0664326 & 0.0461406 & 0.085 & 0.0124573 & 0.0239326 & 0.0036406 \\
1997 & 0.0968111 & 0.0661232 & 0.0459841 & 0.086 & 0.0108111 & 0.0231232 & 0.0029841 \\
1998 & 0.0947737 & 0.0633195 & 0.0429903 & 0.079 & 0.0157737 & 0.0238195 & 0.0034903 \\
1999 & 0.1024808 & 0.0685454 & 0.0465407 & 0.079 & 0.0234808 & 0.0290454 & 0.0070407 \\
2000 & 0.0966913 & 0.0643896 & 0.0435308 & 0.078 & 0.0186913 & 0.0253896 & 0.0045308 \\
\hline
\end{tabular}

Table 2.b. Polarization evidence (2 groups)

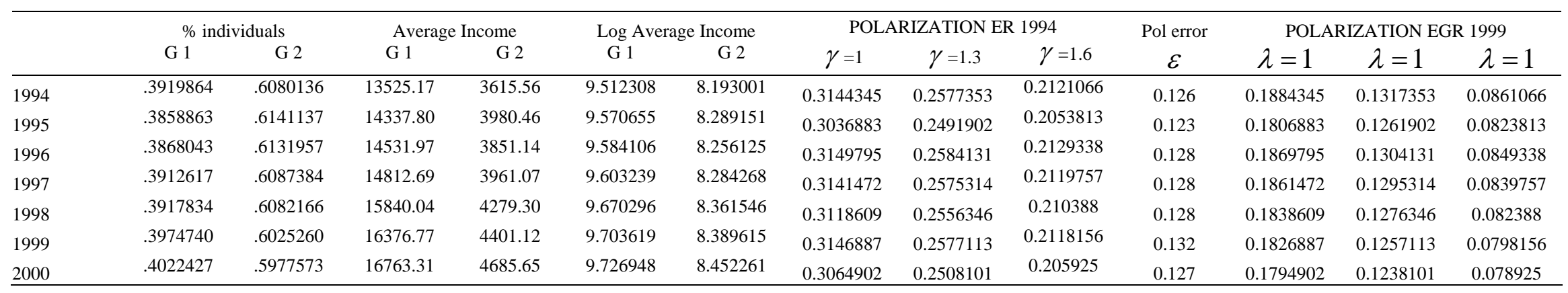


Table 3. Deprivation evidence (6 groups)

\begin{tabular}{cc}
\hline & DEPRIVATION \\
Net & Gross \\
\hline 7556.59 & 12445.80 \\
7549.04 & 12414.35 \\
7559.39 & 12434.47 \\
7565.94 & 12447.27 \\
7566.22 & 12453.4 \\
7551.86 & 12431.79 \\
7561.80 & 12492.27 \\
\hline
\end{tabular}


Table 4. Mean and Std. dev of dependent and explanatory variables

\begin{tabular}{|c|c|}
\hline Variables & \\
\hline Economic Satisfaction & $\begin{array}{l}3.198 \\
(1.39)\end{array}$ \\
\hline SatDepriv & $\begin{array}{l}1.167 \\
(0.66)\end{array}$ \\
\hline Age & $\begin{array}{l}45.439 \\
(19.31)\end{array}$ \\
\hline $\operatorname{Age}^{2} / 100$ & $\begin{array}{l}24.377 \\
(19.14)\end{array}$ \\
\hline Male & $\begin{array}{c}0.481 \\
(0.50)\end{array}$ \\
\hline Married & $\begin{array}{l}0.589 \\
(0.49)\end{array}$ \\
\hline PrimEduc & $\begin{array}{l}0.661 \\
(0.47)\end{array}$ \\
\hline SeconEduc & $\begin{array}{l}0.179 \\
(0.38)\end{array}$ \\
\hline HighEduc & $\begin{array}{l}0.160 \\
(0.37)\end{array}$ \\
\hline Illness & $\begin{array}{l}0.192 \\
(0.39)\end{array}$ \\
\hline FamSize & $\begin{array}{l}3.634 \\
(1.56)\end{array}$ \\
\hline HouseOwnership & $\begin{array}{l}0.843 \\
(0.36)\end{array}$ \\
\hline Children $<16$ & $\begin{array}{l}0.539 \\
(0.86)\end{array}$ \\
\hline Unemployed & $\begin{array}{l}0.087 \\
(0.28)\end{array}$ \\
\hline PublicSector & $\begin{array}{l}0.076 \\
(0.27)\end{array}$ \\
\hline ServiceSector & $\begin{array}{l}0.257 \\
(0.44)\end{array}$ \\
\hline Fulltime & $\begin{array}{l}0.373 \\
(0.48)\end{array}$ \\
\hline IncomeSource & $\begin{array}{l}1.834 \\
(1.79)\end{array}$ \\
\hline Dummy PrivTransf & $\begin{array}{l}0.012 \\
(0.11)\end{array}$ \\
\hline Dummy PubTransf & $\begin{array}{l}0.262 \\
(0.44)\end{array}$ \\
\hline Dummy Taxes & $\begin{array}{l}0.421 \\
(0.49)\end{array}$ \\
\hline Dummy UnempTransf & $\begin{array}{l}0.044 \\
(0.20)\end{array}$ \\
\hline Dummy RetWidTransf & $\begin{array}{l}0.162 \\
(0.37)\end{array}$ \\
\hline Dummy RetTransf & $\begin{array}{l}0.120 \\
(0.33)\end{array}$ \\
\hline Dummy WidTransf & $\begin{array}{l}0.050 \\
(0.22)\end{array}$ \\
\hline Dummy MatTransf & $\begin{array}{l}0.009 \\
(0.10)\end{array}$ \\
\hline Dummy IllTransf & $\begin{array}{l}0.035 \\
(0.18)\end{array}$ \\
\hline Dummy StudyTransf & $\begin{array}{l}0.000 \\
(0.02)\end{array}$ \\
\hline PrivTransf & $\begin{array}{l}2058.160 \\
(3031.33)\end{array}$ \\
\hline PubTransf & $\begin{array}{r}5352.110 \\
(5128.54)\end{array}$ \\
\hline Taxes & $\begin{array}{c}3940.06 \\
(9340.79)\end{array}$ \\
\hline UnempTransf & $\begin{array}{c}2959.06 \\
(7249.13)\end{array}$ \\
\hline RetWidTransf & $\begin{array}{r}6594.390 \\
(4262.88)\end{array}$ \\
\hline RetTransf & $\begin{array}{l}7025.000 \\
(4609.01)\end{array}$ \\
\hline WidTransf & $\begin{array}{l}4530.700 \\
(2332.06)\end{array}$ \\
\hline MatTransf & $\begin{array}{l}1220.010 \\
(1507.84)\end{array}$ \\
\hline IllTransf & $\begin{array}{r}4851.510 \\
(3726.46)\end{array}$ \\
\hline
\end{tabular}


Table 5. Relative Deprivation (in both satisfaction and monetary terms)

\begin{tabular}{|c|c|c|c|c|c|c|c|c|c|}
\hline \multirow{2}{*}{ Variables } & \multicolumn{3}{|c|}{ Satisfaction Deprivation } & \multicolumn{3}{|c|}{ Net Individual Income Deprivation } & \multicolumn{3}{|c|}{ Gross Individual Income Deprivation } \\
\hline & 6 Cohorts & 8 Cohorts & 24 Cohorts & 6 Cohorts & 8 Cohorts & 24 Cohorts & 6 Cohorts & 8 Cohorts & 24 Cohorts \\
\hline \multirow{2}{*}{ Dummy PrivT } & 0.4958 & 0.4393 & 0.4315 & 0.1888 & 0.2073 & 0.1993 & 0.5134 & 0.5702 & 0.4041 \\
\hline & {$[0.1718]^{* * *}$} & {$[0.1688]^{* * *}$} & {$[0.1689]^{* *}$} & {$[0.0696]^{* * *}$} & {$[0.0580]^{* * *}$} & {$[0.0764]^{* * *}$} & {$[0.1200]^{* * *}$} & {$[0.1059]^{* * *}$} & {$[0.1209]^{* * *}$} \\
\hline \multirow{2}{*}{ Dummy PubT } & -0.2497 & -0.1954 & -0.1834 & -0.2083 & -0.1486 & -0.1614 & -0.1969 & -0.2828 & -0.1711 \\
\hline & {$[0.0830]^{* * *}$} & {$[0.0807]^{* *}$} & {$[0.0799]^{* *}$} & {$[0.0269]^{* * *}$} & {$[0.0329]^{* * *}$} & {$[0.0383]^{* * *}$} & {$[0.0523]^{* * *}$} & {$[0.0775]^{* * *}$} & {$[0.0763]^{* *}$} \\
\hline \multirow{2}{*}{ Dummy Taxes } & 0.0523 & -0.0503 & 0.0394 & -0.3521 & -0.3188 & -0.4775 & & & \\
\hline & [0.1027] & [0.0995] & [0.1010] & {$[0.0450]^{* * *}$} & {$[0.0508]^{* * *}$} & {$[0.0586]^{* * *}$} & & & \\
\hline \multirow{2}{*}{ Age } & -0.4130 & -0.3200 & -0.3239 & 0.0136 & 0.2380 & 0.1037 & -0.0016 & 0.4885 & 0.2036 \\
\hline & {$[0.0333]^{* * *}$} & {$[0.0330]^{* * *}$} & {$[0.0328]^{* * *}$} & [0.0112] & {$[0.0112]^{* * *}$} & {$[0.0122]^{* * *}$} & [0.0211] & {$[0.0216]^{* * *}$} & {$[0.0220]^{* * *}$} \\
\hline \multirow{2}{*}{$\mathrm{Age}^{2} / 100$} & 0.1602 & 0.0811 & 0.0888 & 0.0378 & -0.1192 & -0.0385 & 0.0171 & -0.3667 & -0.1524 \\
\hline & {$[0.0310]^{* * *}$} & {$[0.0317]^{* *}$} & {$[0.0315]^{* * *}$} & {$[0.0100]^{* * *}$} & {$[0.0106]^{* * *}$} & {$[0.0116]^{* * *}$} & [0.0175] & {$[0.0197] * * *$} & {$[0.0208]^{* * *}$} \\
\hline \multirow{2}{*}{ FamSize } & 0.1464 & 0.1252 & 0.1370 & 0.0745 & 0.0441 & 0.0423 & 0.1295 & 0.0836 & 0.0809 \\
\hline & {$[0.0400]^{* * *}$} & {$[0.0394]^{* * *}$} & {$[0.0391]^{* * *}$} & {$[0.0162]^{* * *}$} & {$[0.0178]^{* *}$} & {$[0.0192]^{* *}$} & {$[0.0293]^{* * *}$} & {$[0.0378]^{* *}$} & {$[0.0357]^{* *}$} \\
\hline \multirow{2}{*}{ HouseOwnership } & -0.1094 & -0.1046 & -0.0958 & 0.0558 & 0.0250 & 0.0421 & 0.0419 & 0.0984 & 0.1132 \\
\hline & [0.1009] & [0.0999] & [0.0990] & [0.0393] & [0.0375] & {$[0.0412]$} & {$[0.0756]$} & {$[0.0812]$} & {$[0.0816]$} \\
\hline \multirow{2}{*}{ Married } & -0.9946 & -0.9764 & -0.9857 & -0.0632 & -0.1691 & -0.0743 & 0.0243 & -0.1569 & 0.0029 \\
\hline & {$[0.1447]^{* * *}$} & {$[0.1413]^{* * *}$} & {$[0.1415]^{* * *}$} & [0.0509] & {$[0.0507]^{* * *}$} & {$[0.0544]$} & {$[0.0870]$} & {$[0.1140]$} & [0.1062] \\
\hline \multirow{2}{*}{ Unemployed } & 2.0669 & 1.9257 & 1.8651 & 0.0908 & 0.0486 & 0.0867 & 0.0450 & -0.0136 & -0.0372 \\
\hline & {$[0.1174]^{* * *}$} & {$[0.1135]^{* * *}$} & {$[0.1128]^{* * *}$} & {$[0.0320]^{* * *}$} & {$[0.0504]$} & {$[0.0403]^{* *}$} & [0.0559] & [0.1273] & [0.0793] \\
\hline \multirow{2}{*}{ IncomeSource } & -0.0249 & -0.0226 & -0.0219 & -0.0188 & -0.0123 & -0.0073 & -0.0440 & -0.0414 & -0.0342 \\
\hline & {$[0.0175]$} & {$[0.0171]$} & [0.0170] & {$[0.0069]^{* * *}$} & {$[0.0057]^{* *}$} & [0.0068] & {$[0.0118]^{* * *}$} & {$[0.0118] * * *$} & {$[0.0120]^{* * *}$} \\
\hline \multirow{2}{*}{ SeconEduc } & 0.6314 & 0.0967 & 0.8239 & 1.3598 & 0.0185 & 1.1942 & 2.8640 & -0.0324 & 2.5424 \\
\hline & {$[0.1189]^{* * *}$} & [0.1155] & {$[0.1193]^{* * *}$} & {$[0.0430]^{* * *}$} & {$[0.0416]$} & {$[0.0573]^{* * *}$} & {$[0.0749]^{* * *}$} & {$[0.0916]$} & {$[0.0983]^{* * *}$} \\
\hline \multirow{2}{*}{ HighEduc } & 1.4205 & 0.1957 & 1.2742 & 4.6230 & -0.2616 & 3.7276 & 10.2304 & -0.4218 & 8.3216 \\
\hline & {$[0.1740]^{* * *}$} & [0.1609] & {$[0.1712]^{* * *}$} & {$[0.0640]^{* * *}$} & {$[0.0576]^{* * *}$} & {$[0.0822]^{* * *}$} & {$[0.1315]^{* * *}$} & {$[0.1269]^{* * *}$} & {$[0.1641]^{* * *}$} \\
\hline \multirow{2}{*}{ Children $<16$} & 0.1030 & 0.0727 & 0.0701 & -0.0875 & 0.0190 & 0.0918 & -0.1077 & 0.1858 & 0.2668 \\
\hline & {$[0.0601]^{*}$} & {$[0.0600]$} & [0.0590] & {$[0.0313]^{* * *}$} & [0.0343] & {$[0.0339]^{* * *}$} & [0.0709] & {$[0.0727]^{* *}$} & {$[0.0652]^{* * *}$} \\
\hline \multirow{2}{*}{ Illness } & 0.2962 & 0.3563 & 0.3447 & -0.0844 & -0.0967 & -0.1115 & -0.1276 & -0.1440 & -0.1755 \\
\hline & {$[0.0670]^{* * *}$} & {$[0.0698]^{* * *}$} & {$[0.0688]^{* * *}$} & {$[0.0283]^{* * *}$} & {$[0.0285] * * *$} & {$[0.0330]^{* * *}$} & {$[0.0447]^{* * *}$} & {$[0.0570]^{* *}$} & {$[0.0616]^{* * *}$} \\
\hline \multirow{2}{*}{ PublicSector } & -0.5311 & -0.4241 & -0.4779 & -0.1588 & -0.0386 & -0.0498 & -0.1103 & 0.2730 & 0.1226 \\
\hline & {$[0.1592]^{* * *}$} & {$[0.1510]^{* * *}$} & {$[0.1546]^{* * *}$} & {$[0.0709]^{* *}$} & {$[0.0717]$} & {$[0.0782]$} & {$[0.1346]$} & [0.1811] & {$[0.1826]$} \\
\hline \multirow{2}{*}{ ServiceSector } & -0.2175 & -0.1554 & -0.2224 & 0.0930 & 0.1207 & 0.1489 & 0.0757 & 0.0966 & 0.1356 \\
\hline & {$[0.1049]^{* *}$} & {$[0.1016]$} & {$[0.1011]^{* *}$} & [0.0528]* & {$[0.0576]^{* *}$} & {$[0.0686]^{* *}$} & [0.1153] & [0.1190] & [0.1330] \\
\hline \multirow{2}{*}{ FullTime } & -1.4713 & -1.4188 & -1.4579 & -0.2967 & -0.2703 & -0.3189 & -0.2306 & -0.1157 & -0.5391 \\
\hline & {$[0.1207]^{* * *}$} & {$[0.1164]^{* * *}$} & {$[0.1170]^{* * *}$} & {$[0.0427]^{* * *}$} & {$[0.0450]^{* * *}$} & {$[0.0524]^{* * *}$} & {$[0.0671]^{* * *}$} & [0.1041] & {$[0.0960] * * *$} \\
\hline & 30.9170 & 28.9454 & 28.4758 & 2.5160 & -2.4933 & -0.1554 & 5.3989 & -4.5728 & -0.3215 \\
\hline Constant & {$[0.8843]^{* * *}$} & {$[0.8629]^{* * *}$} & {$[0.8591]^{* * *}$} & {$[0.3629]^{* * *}$} & {$[0.3532] * * *$} & {$[0.3896]$} & {$[0.6797]^{* * *}$} & {$[0.7003]^{* * *}$} & {$[0.6855]$} \\
\hline $\mathrm{F}$ & 86.22 & 74.21 & 49.12 & 286.22 & 65.01 & 81.83 & 307.73 & 51.63 & 100.42 \\
\hline $\mathrm{F}$ & {$[0.0000]$} & {$[0.0000]$} & {$[0.0000]$} & {$[0.0000]$} & {$[0.0000]$} & {$[0.0000]$} & {$[0.0000]$} & {$[0.0000]$} & {$[0.0000]$} \\
\hline & 12890.36 & 13232.80 & 13174.66 & 26918.07 & 23736.61 & 12267.03 & 35857.12 & 32726.57 & 19450.07 \\
\hline LM & {$[0.0000]$} & {$[0.0000]$} & {$[0.0000]$} & {$[0.0000]$} & {$[0.0000]$} & {$[0.0000]$} & {$[0.0000]$} & {$[0.0000]$} & {$[0.0000]$} \\
\hline Наизman & 500.43 & 534.54 & 538.25 & 2837.58 & 1914.84 & & 1888.82 & & 3726.78 \\
\hline Hausman & {$[0.0000]$} & {$[0.0000]$} & {$[0.0000]$} & {$[0.0000]$} & {$[0.0000]$} & & {$[0.0000]$} & & {$[0.0000]$} \\
\hline Observations & 69764 & 69803 & 69764 & 71090 & 71136 & 71090 & 71090 & 71136 & 71090 \\
\hline Number of PID & 16759 & 16767 & 16759 & 16853 & 16862 & 16853 & 16853 & 16862 & 16853 \\
\hline R-squared & 0.05 & 0.04 & 0.04 & 0.11 & 0.03 & 0.06 & 0.12 & 0.02 & 0.07 \\
\hline
\end{tabular}

(I) Relative Deprivation (Public Transfers aggregated)

(II) Relative Deprivation (Public Transfers not individual but aggregated)

(III) Relative Deprivation (Amount of Transfers) 
Table 6.a. Relative Deprivation (in both satisfaction and monetary terms) differentiating public transfers

\begin{tabular}{|c|c|c|c|c|c|c|c|c|c|}
\hline \multirow{2}{*}{ Variables } & \multicolumn{3}{|c|}{ Satisfaction Deprivation } & \multicolumn{3}{|c|}{ Net Individual Income Deprivation } & \multicolumn{3}{|c|}{ Gross Individual Income Deprivation } \\
\hline & 6 Cohorts & 8 Cohorts & 24 Cohorts & 6 Cohorts & 8 Cohorts & 24 Cohorts & 6 Cohorts & 8 Cohorts & 24 Cohorts \\
\hline \multirow{2}{*}{ D PrivTransf } & 0.4938 & 0.4387 & 0.4329 & 0.2042 & 0.2113 & 0.1995 & 0.5566 & 0.5825 & 0.4123 \\
\hline & {$[0.1718]^{* * *}$} & {$[0.1689]^{* * *}$} & {$[0.1690]^{* *}$} & {$[0.0693]^{* * *}$} & {$[0.0577]^{* * *}$} & {$[0.0762] * * *$} & {$[0.1188]^{* * *}$} & {$[0.1050]^{* * *}$} & {$[0.1198]^{* * *}$} \\
\hline \multirow{2}{*}{ D UnempTransf ${ }^{\mathrm{i}}$} & -0.0394 & 0.0022 & -0.0067 & 0.1606 & -0.0308 & -0.0169 & 0.4714 & -0.0588 & -0.0621 \\
\hline & {$[0.0259]$} & [0.0084] & [0.0074] & {$[0.0161]^{* * *}$} & {$[0.0041]^{* * *}$} & {$[0.0044]^{* * *}$} & {$[0.0396]^{* * *}$} & {$[0.0091]^{* * *}$} & {$[0.0089] * * *$} \\
\hline \multirow{3}{*}{ D RetireTransf } & -0.8474 & -0.7103 & -0.6475 & -0.4235 & -0.5853 & -0.6437 & -0.5664 & -1.2105 & -1.1855 \\
\hline & {$[0.1439]^{* * *}$} & {$[0.1503]^{* * *}$} & {$[0.1491]^{* * *}$} & {$[0.0502]^{* * *}$} & {$[0.0802]^{* * *}$} & {$[0.0847]^{* * *}$} & {$[0.1081]^{* * *}$} & {$[0.2171] * * *$} & {$[0.1909]^{* * *}$} \\
\hline & -0.2355 & -0.1782 & -0.1008 & -0.3472 & -0.2726 & -0.3936 & -0.1946 & -0.5499 & -0.4849 \\
\hline D WidowTransf & [0.2055] & {$[0.2159]$} & [0.2186] & {$[0.0670]^{* * *}$} & {$[0.0992]^{* * *}$} & {$[0.0851]^{* * *}$} & {$[0.0860]^{* *}$} & {$[0.2521]^{* *}$} & {$[0.1854]^{* * *}$} \\
\hline \multirow{3}{*}{ D MatTransf } & -0.0157 & -0.0469 & -0.0344 & 0.0201 & 0.1063 & 0.0408 & 0.3258 & 0.5494 & 0.4973 \\
\hline & [0.1794] & [0.1824] & [0.1743] & [0.0607] & [0.1292] & [0.1318] & {$[0.1590]^{* *}$} & {$[0.3263]^{*}$} & [0.3211] \\
\hline & -0.2950 & -0.2581 & -0.2317 & -0.2385 & 0.0284 & -0.1268 & -0.2436 & 0.1323 & -0.1985 \\
\hline D IllTransf & {$[0.1506]^{*}$} & [0.1558]* & {$[0.1513]$} & {$[0.0401]^{* * *}$} & [0.0557] & [0.0695]* & {$[0.0805]^{* * *}$} & [0.1359] & {$[0.1256]$} \\
\hline \multirow[b]{2}{*}{ D StudyTransf } & 0.4367 & 0.4995 & 0.6310 & 0.3048 & 0.3219 & 0.4470 & 0.5109 & 0.8555 & 1.1450 \\
\hline & [0.9657] & [0.9546] & [0.9103] & {$[0.1706]^{*}$} & {$[0.1839]^{*}$} & {$[0.1813]^{* *}$} & {$[0.2388]^{* *}$} & {$[0.2539] * * *$} & {$[0.2968]^{* * *}$} \\
\hline \multirow{2}{*}{ D Taxes ${ }^{\mathrm{i}}$} & 0.0155 & -0.0748 & 0.0171 & -0.3024 & -0.3312 & -0.5068 & & & \\
\hline & [0.1034] & [0.0999] & [0.1015] & {$[0.0454]^{* * *}$} & {$[0.0501]^{* * *}$} & {$[0.0585]^{* * *}$} & & & \\
\hline \multirow[b]{2}{*}{ Age } & -0.4895 & -0.3089 & -0.3518 & 0.3314 & 0.0944 & 0.0305 & 0.9232 & 0.2133 & -0.0648 \\
\hline & {$[0.0602]^{* * *}$} & {$[0.0511]^{* * *}$} & {$[0.0459]^{* * *}$} & {$[0.0329]^{* * *}$} & {$[0.0212]^{* * *}$} & {$[0.0219]$} & {$[0.0800]^{* * *}$} & {$[0.0445]^{* * *}$} & [0.0401] \\
\hline \multirow[b]{2}{*}{ Age $^{2} / 100$} & 0.1716 & 0.0815 & 0.1130 & 0.0287 & -0.0195 & 0.0157 & -0.0113 & -0.1734 & 0.0325 \\
\hline & {$[0.0312]^{* * *}$} & {$[0.0406]^{* *}$} & {$[0.0375]^{* * *}$} & {$[0.0101]^{* * *}$} & [0.0144] & {$[0.0143]$} & {$[0.0174]$} & {$[0.0300]^{* * *}$} & {$[0.0253]$} \\
\hline \multirow[b]{2}{*}{ FamSize } & 0.1435 & 0.1213 & 0.1366 & 0.0693 & 0.0447 & 0.0394 & 0.1212 & 0.0841 & 0.0827 \\
\hline & {$[0.0401]^{* * *}$} & {$[0.0395]^{* * *}$} & {$[0.0392]^{* * *}$} & {$[0.0161]^{* * *}$} & {$[0.0181]^{* *}$} & {$[0.0193]^{* *}$} & {$[0.0289]^{* * *}$} & {$[0.0385]^{* *}$} & {$[0.0360]^{* *}$} \\
\hline \multirow[b]{2}{*}{ HouseOwnership } & -0.1094 & -0.1055 & -0.0969 & 0.0524 & 0.0216 & 0.0402 & 0.0348 & 0.0937 & 0.1120 \\
\hline & [0.1009] & [0.0999] & {$[0.0990]$} & {$[0.0391]$} & [0.0372] & {$[0.0411]$} & {$[0.0749]$} & {$[0.0807]$} & {$[0.0811]$} \\
\hline \multirow[b]{2}{*}{ Married } & -0.9998 & -0.9806 & -0.9831 & -0.1030 & -0.1998 & -0.1132 & -0.0240 & -0.2247 & -0.0561 \\
\hline & {$[0.1468]^{* * *}$} & {$[0.1432]^{* * *}$} & {$[0.1435]^{* * *}$} & {$[0.0522]^{* *}$} & {$[0.0541]^{* * *}$} & {$[0.0552]^{* *}$} & {$[0.0882]$} & {$[0.1251]^{*}$} & [0.1117] \\
\hline \multirow{2}{*}{ Unemployed } & 1.9616 & 1.8370 & 1.7893 & 0.0340 & -0.0080 & 0.0186 & 0.0087 & -0.1350 & -0.1593 \\
\hline & {$[0.1188]^{* * *}$} & {$[0.1147]^{* * *}$} & {$[0.1141]^{* * *}$} & {$[0.0316]$} & {$[0.0472]$} & [0.0385] & {$[0.0535]$} & {$[0.1171]$} & {$[0.0728]^{* *}$} \\
\hline
\end{tabular}




\begin{tabular}{|c|c|c|c|c|c|c|c|c|c|}
\hline \multirow[b]{2}{*}{ SeconEduc } & 0.5814 & 0.0982 & 0.7991 & 1.5610 & 0.0173 & 1.1325 & 3.4758 & -0.0379 & 2.3048 \\
\hline & {$[0.1235]^{* * *}$} & [0.1155] & {$[0.1229]^{* * *}$} & {$[0.0472]^{* * *}$} & {$[0.0415]$} & {$[0.0584]^{* * *}$} & {$[0.0906]^{* * *}$} & [0.0911] & {$[0.1007]^{* * *}$} \\
\hline \multirow[b]{2}{*}{ HighEduc } & 1.1964 & 0.2162 & 1.2460 & 5.6488 & -0.2400 & 3.6301 & 13.2498 & -0.3831 & 7.9115 \\
\hline & {$[0.2348]^{* * *}$} & [0.1609] & {$[0.1790]^{* * *}$} & {$[0.1130]^{* * *}$} & {$[0.0574]^{* * *}$} & {$[0.0859]^{* * *}$} & {$[0.2648]^{* * *}$} & {$[0.1272]^{* * *}$} & {$[0.1734]^{* * *}$} \\
\hline \multirow{2}{*}{ Children $<16$} & 0.1017 & 0.0731 & 0.0600 & -0.0942 & -0.0163 & 0.0728 & -0.1305 & 0.1130 & 0.1893 \\
\hline & {$[0.0602]^{*}$} & [0.0609] & [0.0598] & {$[0.0312]^{* * *}$} & [0.0337] & {$[0.0336]^{* *}$} & {$[0.0712]^{*}$} & {$[0.0716]$} & {$[0.0652]^{* * *}$} \\
\hline \multirow{2}{*}{ IncomeSource } & -0.0237 & -0.0214 & -0.0208 & -0.0176 & -0.0114 & -0.0059 & -0.0412 & -0.0394 & -0.0304 \\
\hline & [0.0175] & [0.0171] & {$[0.0170]$} & {$[0.0069]^{* *}$} & {$[0.0056]^{* *}$} & [0.0068] & {$[0.0116]^{* * *}$} & {$[0.0117]^{* * *}$} & {$[0.0118]^{* *}$} \\
\hline \multirow[b]{2}{*}{ Illness } & 0.2984 & 0.3570 & 0.3442 & -0.0905 & -0.1004 & -0.1138 & -0.1475 & -0.1517 & -0.1832 \\
\hline & {$[0.0671]^{* * *}$} & {$[0.0698]^{* * *}$} & {$[0.0688]^{* * *}$} & {$[0.0281]^{* * *}$} & {$[0.0285]^{* * *}$} & {$[0.0329]^{* * *}$} & {$[0.0445]^{* * *}$} & {$[0.0570]^{* * *}$} & {$[0.0615]^{* * *}$} \\
\hline \multirow[b]{2}{*}{ PublicSector } & -0.5597 & -0.4482 & -0.5002 & -0.1737 & -0.0541 & -0.0692 & -0.1162 & 0.2383 & 0.0766 \\
\hline & {$[0.1592]^{* * *}$} & {$[0.1510]^{* * *}$} & {$[0.1546]^{* * *}$} & {$[0.0711]^{* *}$} & [0.0707] & {$[0.0771]$} & [0.1337] & [0.1779] & [0.1790] \\
\hline \multirow{2}{*}{ ServiceSector } & -0.2157 & -0.1538 & -0.2214 & 0.0880 & 0.1194 & 0.1513 & 0.0993 & 0.0834 & 0.1139 \\
\hline & {$[0.1048]^{* *}$} & [0.1015] & {$[0.1011]^{* *}$} & {$[0.0526]^{*}$} & {$[0.0573]^{* *}$} & {$[0.0683]^{* *}$} & [0.1149] & [0.1171] & [0.1315] \\
\hline \multirow[b]{2}{*}{ FullTime } & -1.5027 & -1.4561 & -1.4831 & -0.3347 & -0.2869 & -0.3398 & -0.2507 & -0.1669 & -0.6195 \\
\hline & {$[0.1211]^{* * *}$} & {$[0.1167]^{* * *}$} & {$[0.1173]^{* * *}$} & {$[0.0431]^{* * *}$} & {$[0.0450]^{* * *}$} & {$[0.0526]^{* * *}$} & {$[0.0644]^{* * *}$} & {$[0.0985]^{*}$} & {$[0.0931]^{* * *}$} \\
\hline \multirow[b]{2}{*}{ Constant } & 35.2058 & 28.4975 & 29.3624 & -15.5830 & 2.2727 & 2.3164 & -47.5318 & 4.5355 & 8.9028 \\
\hline & {$[3.0120]^{* * *}$} & {$[1.5745]^{* * *}$} & {$[1.4034]^{* * *}$} & {$[1.8572]^{* * *}$} & {$[0.7414]^{* * *}$} & {$[0.7962]^{* * *}$} & {$[4.5710]^{* * *}$} & {$[1.5611]^{* * *}$} & {$[1.4788]^{* * *}$} \\
\hline \multirow[b]{2}{*}{$\mathrm{F}$} & 73.53 & 63.73 & 44.41 & 247.27 & 62.13 & 76.48 & 283.37 & 50.44 & 93.59 \\
\hline & {$[0.0000]$} & {$[0.0000]$} & {$[0.0000]$} & {$[0.0000]$} & {$[0.0000]$} & {$[0.0000]$} & {$[0.0000]$} & {$[0.0000]$} & {$[0.0000]$} \\
\hline \multirow[b]{2}{*}{ LM } & 12567.79 & 13032.46 & 12994.80 & 18298.41 & 21741.63 & 10723.43 & 30766.86 & 31086.21 & 17792.37 \\
\hline & {$[0.0000]$} & {$[0.0000]$} & {$[0.0000]$} & {$[0.0000]$} & {$[0.0000]$} & {$[0.0000]$} & {$[0.0000]$} & {$[0.0000]$} & {$[0.0000]$} \\
\hline \multirow[b]{2}{*}{ Hausman } & 539.14 & 540.41 & 547.92 & 4583.19 & 3529.91 & 3522.32 & 1672.20 & 2125.10 & 1136.08 \\
\hline & {$[0.0000]$} & {$[0.0000]$} & {$[0.0000]$} & {$[0.0000]$} & {$[0.0000]$} & {$[0.0000]$} & [0.0000] & {$[0.0000]$} & {$[0.0000]$} \\
\hline Observations & 69763 & 69803 & 69763 & 71090 & 71136 & 71090 & 71090 & 71136 & 71090 \\
\hline Number of PID & 16759 & 16767 & 16759 & 16853 & & & 16853 & 16862 & 16853 \\
\hline R-squared & 0.05 & 0.04 & 0.04 & 0.12 & & & 0.13 & 0.02 & 0.07 \\
\hline
\end{tabular}


Table 6.b. Relative Deprivation (in both satisfaction and monetary terms) differentiating public transfers (6 waves)

\begin{tabular}{|c|c|c|c|c|c|c|c|c|c|}
\hline \multirow{2}{*}{ Variables } & \multicolumn{3}{|c|}{ Satisfaction Deprivation } & \multicolumn{3}{|c|}{ Net Individual Income Deprivation } & \multicolumn{3}{|c|}{ Gross Individual Income Deprivation } \\
\hline & 6 Cohorts & 8 Cohorts & 24 Cohorts & 6 Cohorts & 8 Cohorts & 24 Cohorts & 6 Cohorts & 8 Cohorts & 24 Cohorts \\
\hline \multirow{2}{*}{ D PrivTransf } & 0.4891 & 0.4264 & 0.4351 & 0.1930 & 0.1762 & 0.1699 & 0.5565 & 0.5288 & 0.3681 \\
\hline & {$[0.1830]^{* * *}$} & {$[0.1799]^{* *}$} & {$[0.1803]^{* *}$} & {$[0.0587]^{* * *}$} & {$[0.0641]^{* * *}$} & {$[0.0810]^{* *}$} & {$[0.1169] * * *$} & {$[0.1139] * * *$} & {$[0.1293]^{* * *}$} \\
\hline \multirow{2}{*}{ D UnempTransf ${ }^{\mathrm{i}}$} & -0.0493 & -0.0006 & -0.0133 & 0.2137 & -0.0547 & -0.0308 & 0.7016 & -0.0951 & -0.0734 \\
\hline & [0.0309] & [0.0094] & {$[0.0082]$} & {$[0.0215]^{* * *}$} & {$[0.0043]^{* * *}$} & {$[0.0048]^{* * *}$} & {$[0.0544]^{* * *}$} & {$[0.0102]^{* * *}$} & {$[0.0108]^{* * *}$} \\
\hline \multirow{2}{*}{ D RetireTransf } & -0.7544 & -0.6195 & -0.5760 & -0.3659 & -0.4843 & -0.5883 & -0.5637 & -0.9895 & -1.0964 \\
\hline & {$[0.1590]^{* * *}$} & {$[0.1665]^{* * *}$} & {$[0.1651]^{* * *}$} & {$[0.0408]^{* * *}$} & {$[0.0868]^{* * *}$} & {$[0.0790]^{* * *}$} & {$[0.0934]^{* * *}$} & {$[0.2463]^{* * *}$} & {$[0.2003]^{* * *}$} \\
\hline \multirow{2}{*}{ D WidowTransf } & -0.1428 & -0.0691 & 0.0017 & -0.2550 & -0.2683 & -0.2902 & -0.1320 & -0.5463 & -0.3361 \\
\hline & [0.2251] & [0.2369] & [0.2407] & {$[0.0720]^{* * *}$} & {$[0.1157]^{* *}$} & {$[0.0849]^{* * *}$} & [0.0909] & {$[0.2848]^{*}$} & {$[0.1960]^{*}$} \\
\hline \multirow{2}{*}{ D MatTransf $^{\mathrm{i}}$} & -0.0997 & -0.0349 & -0.0299 & 0.1505 & 0.0997 & 0.0738 & 0.2814 & 0.3323 & 0.1812 \\
\hline & {$[0.0428]^{* *}$} & {$[0.0388]$} & {$[0.0318]$} & {$[0.0173]^{* * *}$} & {$[0.0154]^{* * *}$} & {$[0.0138]^{* * *}$} & {$[0.0396] * * *$} & {$[0.0319] * * *$} & {$[0.0249]^{* * *}$} \\
\hline \multirow[t]{2}{*}{ D IllTransf } & -0.2819 & -0.2537 & -0.2368 & -0.1670 & 0.0891 & -0.0992 & -0.2306 & 0.2879 & -0.1944 \\
\hline & {$[0.1679]^{*}$} & [0.1736] & {$[0.1685]$} & {$[0.0386]^{* * *}$} & [0.0614] & [0.0597]* & {$[0.0736]^{* * *}$} & [0.1582]* & {$[0.1323]$} \\
\hline D StudyTransf & $\begin{array}{l}1.9804 \\
{[11678] *}\end{array}$ & 2.0413 & 2.0110 & 0.3806 & 0.4251 & 0.5910 & 0.4509 & 0.8542 & $1.101 /$ \\
\hline \multirow{2}{*}{ D Taxes ${ }^{\mathrm{i}}$} & 0.0553 & $\begin{array}{c}{[1.1334]} \\
-0.0194\end{array}$ & $\begin{array}{c}{[1.112 /]^{*}} \\
0.0733\end{array}$ & $\begin{array}{c}{[0.1988]^{*}} \\
-0.2185\end{array}$ & $\begin{array}{c}{[0.1170]^{* * *}} \\
-0.2597\end{array}$ & $\begin{array}{c}{[0.1802]^{* . *}} \\
-0.3938\end{array}$ & {$[0.3019]$} & {$[0.1975]^{* * *}$} & {$[0.2941]^{* * *}$} \\
\hline & [0.1112] & {$[0.1071]$} & [0.1090] & {$[0.0404]^{* * *}$} & {$[0.0499]^{* * *}$} & {$[0.0555]^{* * *}$} & & & \\
\hline \multirow{2}{*}{ Age } & -0.4667 & -0.3007 & -0.3608 & 0.5051 & 0.0263 & 0.0242 & 1.6439 & 0.2454 & 0.0520 \\
\hline & {$[0.0739] * * *$} & {$[0.0583]^{* * *}$} & {$[0.0529]^{* * *}$} & {$[0.0461]^{* * *}$} & [0.0222] & {$[0.0235]$} & {$[0.1199]^{* * *}$} & {$[0.0514]^{* * *}$} & {$[0.0517]$} \\
\hline \multirow{2}{*}{$\mathrm{Age}^{2} / 100$} & 0.1392 & 0.1019 & 0.1341 & 0.0304 & 0.0569 & 0.0311 & -0.0414 & -0.0562 & 0.0283 \\
\hline & {$[0.0384]^{* * *}$} & {$[0.0470]^{* *}$} & {$[0.0441]^{* * *}$} & {$[0.0126]^{* *}$} & {$[0.0159]^{* * *}$} & {$[0.0147]^{* *}$} & {$[0.0242]^{*}$} & [0.0337]* & {$[0.0286]$} \\
\hline \multirow{2}{*}{ FamSize } & 0.1167 & 0.1028 & 0.1171 & 0.0653 & 0.0162 & 0.0317 & 0.1400 & 0.0610 & 0.0748 \\
\hline & {$[0.0458]^{* *}$} & {$[0.0454]^{* *}$} & {$[0.0450]^{* * *}$} & {$[0.0141]^{* * *}$} & {$[0.0187]$} & [0.0189]* & {$[0.0314]^{* * *}$} & {$[0.0478]$} & [0.0414]* \\
\hline \multirow{2}{*}{ HouseOwnership } & 0.0281 & 0.0294 & 0.0436 & 0.0036 & 0.0203 & -0.0022 & -0.0532 & 0.0342 & 0.0064 \\
\hline & [0.1111] & {$[0.1100]$} & [0.1090] & {$[0.0361]$} & {$[0.0386]$} & {$[0.0423]$} & [0.0841] & [0.0922] & [0.0898] \\
\hline \multirow{2}{*}{ Married } & -0.9495 & -0.9528 & -0.9396 & -0.1341 & -0.2072 & -0.1339 & -0.0412 & -0.2547 & -0.0877 \\
\hline & {$[0.1662]^{* * *}$} & {$[0.1625]^{* * *}$} & {$[0.1626]^{* * *}$} & {$[0.0558]^{* *}$} & {$[0.0633]^{* * *}$} & {$[0.0627]^{* *}$} & {$[0.1023]$} & {$[0.1440]^{*}$} & [0.1223] \\
\hline \multirow{2}{*}{ Unemployed } & 1.9262 & 1.8050 & 1.7645 & 0.0413 & -0.0049 & 0.0594 & 0.0443 & -0.2011 & -0.1119 \\
\hline & {$[0.1291]^{* * *}$} & {$[0.1245]^{* * *}$} & {$[0.1237]^{* * *}$} & {$[0.0316]$} & {$[0.0542]$} & {$[0.0397]$} & {$[0.0603]$} & [0.1409] & {$[0.0822]$} \\
\hline \multirow{2}{*}{ SeconEduc } & 0.4852 & 0.0759 & 0.6892 & 1.8015 & 0.0299 & 1.2071 & 4.0541 & -0.1129 & 2.6483 \\
\hline & {$[0.1427]^{* * *}$} & {$[0.1347]$} & {$[0.1434]^{* * *}$} & {$[0.0517]^{* * *}$} & {$[0.0481]$} & {$[0.0641]^{* * *}$} & {$[0.1070]^{* * *}$} & [0.1155] & {$[0.1250]^{* * *}$} \\
\hline \multirow{2}{*}{ HighEduc } & 1.3269 & 0.2997 & 1.3399 & 6.1193 & -0.2042 & 3.5010 & 15.2166 & -0.5171 & 7.9464 \\
\hline & {$[0.2842]^{* * *}$} & [0.1902] & {$[0.2128]^{* * *}$} & {$[0.1438]^{* * *}$} & {$[0.0628]^{* * *}$} & {$[0.1031]^{* * *}$} & {$[0.3548]^{* * *}$} & {$[0.1597]^{* * *}$} & {$[0.2274]^{* * *}$} \\
\hline \multirow{2}{*}{ Children $<16$} & 0.0846 & 0.0406 & 0.0222 & -0.0384 & 0.0485 & 0.1031 & -0.0755 & 0.1007 & 0.2081 \\
\hline & {$[0.0688]$} & {$[0.0698]$} & {$[0.0682]$} & [0.0292] & {$[0.0349]$} & {$[0.0325]^{* * *}$} & {$[0.0823]$} & {$[0.0881]$} & {$[0.0736]^{* * *}$} \\
\hline \multirow{2}{*}{ IncomeSource } & -0.0253 & -0.0248 & -0.0237 & -0.0176 & -0.0069 & -0.0062 & -0.0417 & -0.0309 & -0.0294 \\
\hline & {$[0.0194]$} & {$[0.0189]$} & {$[0.0188]$} & {$[0.0067] * * *$} & {$[0.0057]$} & {$[0.0066]$} & {$[0.0113]^{* * *}$} & {$[0.0123]^{* *}$} & {$[0.0117]^{* *}$} \\
\hline \multirow{2}{*}{ Illness } & 0.2993 & 0.3538 & 0.3394 & -0.0902 & -0.0847 & -0.0910 & -0.1754 & -0.1456 & -0.1690 \\
\hline & {$[0.0734]^{* * *}$} & {$[0.0765]^{* * *}$} & {$[0.0754]^{* * *}$} & {$[0.0239] * * *$} & {$[0.0264] * * *$} & {$[0.0308]^{* * *}$} & {$[0.0476] * * *$} & {$[0.0656]^{* *}$} & {$[0.0693]^{* *}$} \\
\hline \multirow[t]{2}{*}{ PublicSector } & $\begin{array}{l}-0.5203 \\
0.1845]^{* * *}\end{array}$ & -0.4062 & $\begin{array}{c}-0.4684 \\
\end{array}$ & -0.2033 & 0.0093 & -0.0936 & -0.0361 & 0.3928 & 0.1034 \\
\hline & {$[0.1845]^{* * *}$} & {$[0.1745]^{* *}$} & {$[0.1791]^{* * *}$} & {$[0.0586]^{* * *}$} & {$[0.0777]$} & {$[0.0835]$} & {$[0.1542]$} & {$[0.2140]^{*}$} & {$[0.2116]$} \\
\hline
\end{tabular}




\begin{tabular}{|c|c|c|c|c|c|c|c|c|c|}
\hline ServiceSector & -0.2551 & -0.1995 & -0.2620 & 0.0564 & 0.0740 & 0.1167 & 0.1210 & 0.0637 & 0.1666 \\
\hline servicesector & {$[0.1164]^{* *}$} & [0.1128]* & {$[0.1122] * *$} & [0.0434] & {$[0.0569]$} & [0.0674]* & {$[0.1357]$} & [0.1433] & [0.1561] \\
\hline & -1.5764 & -1.5241 & -1.5432 & -0.2958 & -0.2628 & -0.2741 & -0.2447 & -0.2807 & -0.5989 \\
\hline Fullime & {$[0.1325]^{* * *}$} & {$[0.1274]^{* * *}$} & {$[0.1282]^{* * *}$} & {$[0.0415]^{* * *}$} & {$[0.0464]^{* * *}$} & {$[0.0515]^{* * *}$} & {$[0.0675]^{* * *}$} & {$[0.1154]^{* *}$} & {$[0.1035]^{* * *}$} \\
\hline Constant & $\begin{array}{c}35.5290 \\
{[3.7189]^{* * *}}\end{array}$ & $\begin{array}{c}27.8505 \\
{[1.8054]^{* * *}}\end{array}$ & $\begin{array}{c}29.5529 \\
{[1.6162]^{* * *}}\end{array}$ & $\begin{array}{c}-25.2433 \\
{[2.7167]^{* * *}}\end{array}$ & $\begin{array}{c}3.9241 \\
{[0.8035]^{* * *}}\end{array}$ & $\begin{array}{c}2.4855 \\
{[0.9226]^{* * *}}\end{array}$ & $\begin{array}{c}-86.2602 \\
{[6.9987]^{* * *}}\end{array}$ & $\begin{array}{c}0.9216 \\
{[1.9579]}\end{array}$ & $\begin{array}{c}3.8766 \\
{[2.1245]^{*}}\end{array}$ \\
\hline $\mathrm{F}$ & $\begin{array}{c}55.78 \\
{[0.0000]}\end{array}$ & $\begin{array}{c}48.37 \\
{[0.0000]}\end{array}$ & $\begin{array}{c}33.78 \\
{[0.0000]}\end{array}$ & $\begin{array}{c}219.55 \\
{[0.0000]}\end{array}$ & $\begin{array}{c}55.98 \\
{[0.0000]}\end{array}$ & $\begin{array}{c}65.66 \\
{[0.0000]}\end{array}$ & $\begin{array}{c}216.03 \\
{[0.0000]}\end{array}$ & $\begin{array}{c}44.13 \\
{[0.0000]}\end{array}$ & $\begin{array}{c}73.38 \\
{[0.0000]}\end{array}$ \\
\hline LM & $\begin{array}{l}10311.36 \\
{[0.0000]}\end{array}$ & $\begin{array}{l}10712.73 \\
{[0.0000]}\end{array}$ & $\begin{array}{l}10694.60 \\
{[0.0000]}\end{array}$ & $\begin{array}{l}15842.28 \\
{[0.0000]}\end{array}$ & $\begin{array}{l}16207.65 \\
{[0.0000]}\end{array}$ & $\begin{array}{l}9521.73 \\
{[0.0000]}\end{array}$ & $\begin{array}{l}21449.93 \\
{[0.0000]}\end{array}$ & $\begin{array}{l}20637.67 \\
{[0.0000]}\end{array}$ & $\begin{array}{l}13184.89 \\
{[0.0000]}\end{array}$ \\
\hline Hausman & $\begin{array}{c}599.30 \\
{[0.0000]}\end{array}$ & $\begin{array}{c}540.34 \\
{[0.0000]}\end{array}$ & $\begin{array}{c}933.21 \\
{[0.0000]}\end{array}$ & & $\begin{array}{l}2906.70 \\
{[0.0000]}\end{array}$ & $\begin{array}{l}1462.79 \\
{[0.0000]}\end{array}$ & $\begin{array}{l}8519.81 \\
{[0.0000]}\end{array}$ & $\begin{array}{l}12562.32 \\
{[0.0000]}\end{array}$ & $\begin{array}{l}2721.97 \\
{[0.0000]}\end{array}$ \\
\hline Observations & 60790 & 60830 & 60790 & 62083 & 62129 & 62083 & 62083 & 62129 & 62083 \\
\hline Number of PID & 16261 & 16270 & 16261 & 16361 & 16371 & 16361 & 16361 & 16371 & 16361 \\
\hline R-squared & 0.05 & 0.04 & 0.04 & 0.14 & 0.03 & 0.06 & 0.13 & 0.02 & 0.07 \\
\hline
\end{tabular}


Table 6.c. Relative Deprivation (in both satisfaction and monetary terms) differentiating public transfers (8 Cohorts)

\begin{tabular}{|c|c|c|c|c|c|c|}
\hline \multirow{2}{*}{$\begin{array}{l}\text { Variables } \\
\text { (8 Cohorts) }\end{array}$} & \multicolumn{2}{|c|}{ Satisfaction Deprivation } & \multicolumn{2}{|c|}{ Net Indiv Income Deprivation } & \multicolumn{2}{|c|}{ Gross Indiv Income Deprivation } \\
\hline & D Mat $(7 w)$ & $\mathrm{D} \mathrm{Mat}^{\mathrm{i}}(6 \mathrm{w})$ & D Mat (7w) & $\mathrm{D} \mathrm{Mat}^{\mathrm{i}}(6 \mathrm{w})$ & D Mat $(7 w)$ & $\operatorname{D~Mat~}^{\mathrm{i}}(6 \mathrm{w})$ \\
\hline \multirow{2}{*}{ D PrivTransf } & 0.4500 & 0.4340 & 0.2130 & 0.1720 & 0.5883 & 0.5219 \\
\hline & {$[0.1689]^{* * *}$} & {$[0.1799]^{* *}$} & {$[0.0564]^{* * *}$} & {$[0.0628]^{* * *}$} & {$[0.1020]^{* * *}$} & {$[0.1105]^{* * *}$} \\
\hline \multirow{2}{*}{ D UnempTransf ${ }^{\mathrm{i}}$} & 0.0051 & 0.0061 & -0.0962 & -0.1183 & -0.1879 & -0.2258 \\
\hline & [0.0093] & {$[0.0104]$} & {$[0.0038]^{* * *}$} & {$[0.0040]^{* * *}$} & {$[0.0086]^{* * *}$} & {$[0.0101]^{* * *}$} \\
\hline \multirow{2}{*}{ D RetireTransf } & -0.8032 & -0.4615 & -4.0042 & -3.8057 & -8.5788 & -8.6063 \\
\hline & {$[0.3058]^{* * *}$} & {$[0.3533]$} & {$[0.2172]^{* * *}$} & {$[0.2411]^{* * *}$} & {$[0.5196]^{* * *}$} & {$[0.5634]^{* * *}$} \\
\hline \multirow{2}{*}{ D WidowTransf } & 2.4461 & 2.4745 & -6.5615 & -6.9728 & -10.8352 & -11.7007 \\
\hline & {$[1.0160]^{* *}$} & {$[1.2217]^{* *}$} & {$[0.2789] * * *$} & {$[0.3293]^{* * *}$} & {$[0.6303]^{* * *}$} & {$[0.6919] * * *$} \\
\hline \multirow{2}{*}{ D MatTransf ${ }^{\mathrm{i}}$} & -0.0133 & -0.0325 & 0.1349 & 0.1651 & 0.6073 & 0.4835 \\
\hline & [0.1822] & [0.0393] & [0.1287] & {$[0.0157]^{* * *}$} & {$[0.3272]^{*}$} & {$[0.0331]^{* * *}$} \\
\hline \multirow{2}{*}{ D IllTransf } & 0.0548 & 0.0414 & 0.1001 & 0.1538 & 0.2792 & 0.4006 \\
\hline & [0.1391] & {$[0.1542]$} & {$[0.0371]^{* * *}$} & {$[0.0376]^{* * *}$} & {$[0.0815]^{* * *}$} & {$[0.0874] * * *$} \\
\hline \multirow{2}{*}{ D StudyTransf } & 0.5319 & 2.0762 & 0.1555 & 0.3083 & 0.5042 & 0.6015 \\
\hline & [0.9525] & {$[1.1312]^{*}$} & {$[0.1737]$} & {$[0.1136]^{* * *}$} & {$[0.2283]^{* *}$} & {$[0.1824]^{* * *}$} \\
\hline \multirow{2}{*}{ D Taxes ${ }^{\mathrm{i}}$} & -0.0306 & 0.0171 & -0.3151 & -0.2579 & & \\
\hline & [0.0993] & [0.1064] & {$[0.0500]^{* * *}$} & {$[0.0505]^{* * *}$} & & \\
\hline \multirow{2}{*}{ Age } & -0.3114 & -0.2765 & -0.3359 & -0.3789 & -0.6509 & -0.6004 \\
\hline & {$[0.0578]^{* * *}$} & {$[0.0654]^{* * *}$} & {$[0.0224]^{* * *}$} & {$[0.0228]^{* * *}$} & {$[0.0477]^{* * *}$} & {$[0.0566]^{* * *}$} \\
\hline \multirow{2}{*}{$\operatorname{Age}^{2} / 100$} & 0.0870 & 0.0845 & 0.3859 & 0.4430 & 0.6457 & 0.7597 \\
\hline & {$[0.0482]^{*}$} & {$[0.0551]$} & {$[0.0183]^{* * *}$} & {$[0.0205]^{* * *}$} & {$[0.0390]^{* * *}$} & {$[0.0480]^{* * *}$} \\
\hline \multirow{2}{*}{ FamSize } & 0.1254 & 0.1060 & 0.0253 & 0.0020 & 0.0448 & 0.0311 \\
\hline & {$[0.0395]^{* * *}$} & {$[0.0454]^{* *}$} & {$[0.0176]$} & {$[0.0181]$} & [0.0373] & [0.0465] \\
\hline \multirow{2}{*}{ HouseOwnership } & -0.1076 & 0.0271 & 0.0039 & 0.0105 & 0.0575 & 0.0133 \\
\hline & [0.0999] & {$[0.1100]$} & {$[0.0364]$} & {$[0.0377]$} & {$[0.0795]$} & {$[0.0910]$} \\
\hline \multirow{2}{*}{ Married } & -0.9594 & -0.9477 & -0.1840 & -0.1981 & -0.1841 & -0.2280 \\
\hline & {$[0.1414]^{* * *}$} & {$[0.1611]^{* * *}$} & {$[0.0500]^{* * *}$} & {$[0.0582]^{* * *}$} & [0.1122] & [0.1309]* \\
\hline & 1.9055 & 1.8667 & -0.0290 & -0.0245 & -0.1728 & -0.2498 \\
\hline Unemployed & {$[0.1137]^{* * *}$} & {$[0.1235]^{* * *}$} & [0.0493] & {$[0.0572]$} & [0.1256] & [0.1521] \\
\hline & 0.0935 & 0.0726 & 0.0188 & 0.0248 & -0.0316 & -0.1246 \\
\hline SeconEduc & [0.1155] & [0.1347] & [0.0409] & {$[0.0476]$} & [0.0903] & [0.1144] \\
\hline & 0.2017 & 0.2853 & -0.1908 & -0.1705 & -0.2752 & -0.4425 \\
\hline HighEduc & [0.1609] & [0.1902] & {$[0.0560]^{* * *}$} & {$[0.0616]^{* * *}$} & {$[0.1252]^{* *}$} & {$[0.1580]^{* * *}$} \\
\hline & 0.0736 & 0.0443 & -0.0288 & 0.0288 & 0.0885 & 0.0596 \\
\hline Children< 16 & [0.0609] & [0.0697] & {$[0.0337]$} & [0.0352] & {$[0.0721]$} & [0.0892] \\
\hline & -0.0256 & -0.0277 & -0.0132 & -0.0087 & -0.0439 & -0.0353 \\
\hline Incomesource & [0.0170] & [0.0189] & {$[0.0056]^{* *}$} & {$[0.0056]$} & {$[0.0116]^{* * *}$} & {$[0.0119] * * *$} \\
\hline & 0.3511 & 0.3480 & -0.1168 & -0.0978 & -0.1874 & -0.1766 \\
\hline IIIness & {$[0.0699]^{* * *}$} & {$[0.0765]^{* * *}$} & {$[0.0281]^{* * *}$} & {$[0.0260]^{* * *}$} & {$[0.0561]^{* * *}$} & {$[0.0649] * * *$} \\
\hline PublicSector & -0.4227 & -0.3802 & -0.0677 & -0.0053 & 0.2162 & 0.3617 \\
\hline Publicsector & {$[0.1509]^{* * *}$} & {$[0.1744]^{* *}$} & {$[0.0703]$} & {$[0.0775]$} & [0.1778] & {$[0.2145]^{*}$} \\
\hline & -0.1465 & -0.1918 & 0.1097 & 0.0707 & 0.0766 & 0.0590 \\
\hline ServiceSector & [0.1015] & {$[0.1129]^{*}$} & {$[0.0570]^{*}$} & {$[0.0566]$} & [0.1170] & [0.1437] \\
\hline & -1.4002 & -1.4725 & -0.3228 & -0.2940 & -0.2226 & -0.3539 \\
\hline FullTime & {$[0.1159]^{* * *}$} & {$[0.1266]^{* * *}$} & {$[0.0448]^{* * *}$} & {$[0.0466]^{* * *}$} & {$[0.1017]^{* *}$} & {$[0.1205]^{* * *}$} \\
\hline Conctant & 28.2038 & 26.8111 & 14.0588 & 14.9685 & 27.9738 & 23.6190 \\
\hline Constant & {$[1.7379]^{* * *}$} & {$[1.9830]^{* * *}$} & {$[0.7430]^{* * *}$} & {$[0.7831]^{* * *}$} & {$[1.5881]^{* * *}$} & {$[2.0125]^{* * *}$} \\
\hline$F_{2}$ & 63.40 & 48.12 & 139.32 & 122.10 & 113.33 & 97.85 \\
\hline $\mathrm{F}$ & {$[0.0000]$} & {$[0.0000]$} & {$[0.0000]$} & {$[0.0000]$} & {$[0.0000]$} & {$[0.0000]$} \\
\hline $\mathrm{I} M$ & 13214.26 & 10860.31 & 16340.64 & 11573.28 & 27034.38 & 17483.12 \\
\hline LM & {$[0.0000]$} & {$[0.0000]$} & {$[0.0000]$} & {$[0.0000]$} & {$[0.0000]$} & {$[0.0000]$} \\
\hline & 543.37 & 540.94 & 2463.15 & 26636.56 & 10691.39 & 7326.27 \\
\hline Hausman & {$[0.0000]$} & {$[0.0000]$} & {$[0.0000]$} & {$[0.0000]$} & {$[0.0000]$} & {$[0.0000]$} \\
\hline Observations & 69803 & 60830 & 71136 & 62129 & 71136 & 62129 \\
\hline Number of PID & 16767 & 16270 & 16862 & 16371 & 16862 & 16371 \\
\hline R-squared & 0.04 & 0.04 & 0.05 & 0.06 & 0.04 & 0.04 \\
\hline
\end{tabular}


Table 7. a. Effects of Benefits on Relative Deprivation in Satisfaction (6 Cohorts)

\begin{tabular}{|c|c|c|c|c|c|c|c|c|c|}
\hline Variables (6) & PrivTr & PubTr & Taxes & UnempTr & RetWidTr & MatTr & IllTr & RetTr & WidTr \\
\hline \multirow{2}{*}{ Transfer (i) } & 2.5391 & -1.4796 & -0.1599 & -0.8268 & -1.8800 & -4.1914 & -1.9913 & -2.0473 & -1.2395 \\
\hline & [4.0177] & {$[0.2937]^{* * *}$} & {$[0.0519]^{* * *}$} & {$[0.4751]^{*}$} & {$[0.4308]^{* * *}$} & [2.2181]* & {$[1.8456]$} & {$[0.5483]^{* * *}$} & [1.0377] \\
\hline \multirow{2}{*}{$\operatorname{Transfer}^{2}$ (i) } & -12.5962 & 0.6423 & & 0.3242 & 2.8502 & -13.7143 & 3.1090 & 5.1689 & 1.4100 \\
\hline & [15.5686] & {$[0.1994]^{* * *}$} & & [0.2315] & {$[0.9426]^{* * *}$} & [13.5795] & [8.8600] & {$[1.4120]^{* * *}$} & [1.1355] \\
\hline \multirow{2}{*}{ Age } & 0.0233 & -0.0826 & -0.0315 & 0.0222 & -0.0707 & 0.0112 & -0.1020 & -0.1092 & -0.0552 \\
\hline & [0.0582] & {$[0.0083]^{* * *}$} & {$[0.0049]^{* * *}$} & {$[0.0059]^{* * *}$} & {$[0.0177]^{* * *}$} & [0.0093] & {$[0.0339]^{* * *}$} & {$[0.0287]^{* * *}$} & {$[0.0226]^{* *}$} \\
\hline \multirow{2}{*}{$\mathrm{Age}^{2} / 100$} & -0.0432 & 0.0476 & 0.0001 & -0.0278 & 0.0409 & -0.0165 & 0.0589 & 0.0678 & 0.0253 \\
\hline & [0.0632] & {$[0.0062]^{* * *}$} & [0.0052] & {$[0.0070]^{* * *}$} & {$[0.0123]^{* * *}$} & [0.0106] & {$[0.0300]^{* *}$} & {$[0.0198]^{* * *}$} & {$[0.0157]$} \\
\hline FamSize & -0.0300 & 0.0071 & 0.0251 & 0.0151 & 0.0034 & -0.0022 & 0.0096 & 0.0088 & 0.0021 \\
\hline \multirow[b]{2}{*}{ HouseOwnership } & [0.0894] & [0.0076] & {$[0.0053]^{* * *}$} & {$[0.0075]^{* *}$} & [0.0101] & [0.0145] & [0.0201] & {$[0.0130]$} & [0.0156] \\
\hline & $\begin{array}{l}-0.0634 \\
\end{array}$ & -0.0035 & $\begin{array}{l}-0.0144 \\
-0.01201\end{array}$ & -0.0653 & 0.0284 & -0.1089 & -0.0479 & 0.0591 & -0.0157 \\
\hline \multirow{2}{*}{ Married } & 0.2092 & -0.0859 & -0.0631 & -0.0722 & -0.1164 & -0.1229 & -0.0998 & -0.0903 & 0.0000 \\
\hline & {$[0.2048]$} & {$[0.0308]^{* * *}$} & {$[0.0188]^{* * *}$} & {$[0.0223]^{* * *}$} & {$[0.0425]^{* * *}$} & {$[0.0429]^{* * *}$} & {$[0.0870]$} & {$[0.0453]^{* *}$} & {$[0.0000]$} \\
\hline \multirow{2}{*}{ Unemployed } & 0.2012 & 0.1272 & 0.1735 & 0.1710 & -0.0609 & 0.2145 & 0.0065 & -0.1693 & -0.0289 \\
\hline & {$[0.1213]^{*}$} & {$[0.0212]^{* * *}$} & {$[0.0153]^{* * *}$} & {$[0.0217]^{* * *}$} & {$[0.0763]$} & {$[0.0449]^{* * *}$} & [0.1185] & [0.1705] & {$[0.0836]$} \\
\hline \multirow{2}{*}{ IncomeSource } & 0.0107 & 0.0105 & 0.0013 & 0.0166 & -0.0060 & 0.0246 & 0.0027 & 0.0069 & -0.0239 \\
\hline & [0.0243] & {$[0.0047]^{* *}$} & [0.0033] & {$[0.0058]^{* * *}$} & [0.0128] & {$[0.0108]^{* *}$} & [0.0168] & {$[0.0172]$} & [0.0204] \\
\hline \multirow{2}{*}{ SeconEduc } & 0.1530 & 0.0693 & 0.0445 & 0.0077 & 0.0583 & -0.0314 & 0.0513 & 0.0473 & 0.0788 \\
\hline & {$[0.1821]$} & {$[0.0288]^{* *}$} & {$[0.0147]^{* * *}$} & {$[0.0270]$} & {$[0.0362]$} & [0.0577] & {$[0.0884]$} & {$[0.0394]$} & [0.0835] \\
\hline \multirow{2}{*}{ HighEduc } & 0.4091 & 0.0827 & 0.1065 & -0.0024 & 0.0225 & -0.1115 & 0.1985 & 0.0101 & -0.0455 \\
\hline & [0.3433] & {$[0.0434]^{*}$} & {$[0.0210]^{* * *}$} & [0.0338] & {$[0.0562]$} & [0.0779] & [0.1567] & {$[0.0606]$} & [0.1382] \\
\hline \multirow{2}{*}{ Children<16 } & -0.0902 & -0.0122 & 0.0020 & 0.0178 & 0.0003 & 0.0581 & -0.0256 & -0.0017 & -0.0131 \\
\hline & [0.0950] & [0.0130] & [0.0075] & {$[0.0116]$} & [0.0205] & {$[0.0200]^{* * *}$} & [0.0354] & [0.0273] & [0.0305] \\
\hline \multirow{2}{*}{ Illness } & -0.0170 & 0.0393 & 0.0290 & 0.0731 & 0.0395 & 0.1451 & 0.0689 & 0.0364 & 0.0496 \\
\hline & [0.1180] & {$[0.0094]^{* * *}$} & {$[0.0101]^{* * *}$} & {$[0.0231]^{* * *}$} & {$[0.0106]^{* * *}$} & {$[0.0462]^{* * *}$} & [0.0399]* & {$[0.0125]^{* * *}$} & {$[0.0192]^{* * *}$} \\
\hline PublicSector & $\begin{array}{c}0.3283 \\
{[0.2855]}\end{array}$ & $\begin{array}{c}0.0680 \\
{[0.0413]^{*}}\end{array}$ & $\begin{array}{c}-0.0534 \\
{[0.0174]^{* * *}}\end{array}$ & $\begin{array}{c}-0.0390 \\
{[0.0365]}\end{array}$ & $\begin{array}{c}0.2020 \\
{[0.1065]^{*}}\end{array}$ & $\begin{array}{c}-0.0527 \\
{[0.0664]}\end{array}$ & $\begin{array}{c}0.0934 \\
{[0.1505]}\end{array}$ & $\begin{array}{c}1.3566 \\
{[0.3329]^{* * *}}\end{array}$ & $\begin{array}{c}0.1955 \\
{[0.1021]^{*}}\end{array}$ \\
\hline \multirow{2}{*}{ ServiceSector } & 0.0561 & -0.0214 & -0.0181 & -0.0410 & -0.0318 & -0.0471 & -0.0121 & -0.1789 & 0.0358 \\
\hline & [0.1407] & [0.0258] & [0.0122] & {$[0.0236]^{*}$} & {$[0.0589]$} & [0.0489] & [0.0831] & [0.1328] & {$[0.0673]$} \\
\hline \multirow{2}{*}{ FullTime } & -0.2315 & -0.2163 & -0.1448 & -0.1568 & -0.1892 & -0.1807 & -0.2440 & -0.0123 & -0.2658 \\
\hline & [0.1315]* & {$[0.0236]^{* * *}$} & {$[0.0133]^{* * *}$} & {$[0.0234]^{* * *}$} & {$[0.0651]^{* * *}$} & {$[0.0496]^{* * *}$} & {$[0.0727]^{* * *}$} & [0.1278] & {$[0.0706]^{* * *}$} \\
\hline \multirow{2}{*}{ Constant } & 1.7602 & 4.6929 & 2.8179 & 1.1903 & 4.4907 & 1.6052 & 5.4740 & 5.7534 & 4.2414 \\
\hline & [1.3882] & {$[0.2726]^{* * *}$} & {$[0.1117]^{* * *}$} & {$[0.1179] * * *$} & {$[0.6412]^{* * *}$} & {$[0.2151]^{* * *}$} & {$[0.9725]^{* * *}$} & {$[1.0422]^{* * *}$} & {$[0.8234]^{* * *}$} \\
\hline \multirow{2}{*}{$\mathrm{F}$} & 0.90 & 22.51 & 61.64 & 10.03 & 3.58 & 484.81 & 2.92 & 3.55 & 2.40 \\
\hline & 0.6083 & [0.0000] & {$[0.0000]$} & {$[0.0000]$} & {$[0.0000]$} & {$[0.0000]$} & {$[0.0000]$} & {$[0.0000]$} & 0.0001 \\
\hline \multirow{2}{*}{ LM } & 70.30 & 3935.33 & 6081.55 & 168.54 & 2890.55 & 10.82 & 369.17 & 2056.28 & 889.48 \\
\hline & {$[0.0000]$} & {$[0.0000]$} & {$[0.0000]$} & {$[0.0000]$} & {$[0.0000]$} & 0.0010 & {$[0.0000]$} & {$[0.0000]$} & {$[0.0000]$} \\
\hline \multirow{2}{*}{ Hausman } & 550.83 & 300.84 & 97.44 & & 258.85 & 32.10 & 129.41 & 140.48 & 180.50 \\
\hline & {$[0.0000]$} & {$[0.0000]$} & {$[0.0000]$} & & {$[0.0000]$} & 0.0981 & {$[0.0000]$} & {$[0.0000]$} & {$[0.0000]$} \\
\hline Observations & 1325 & 27760 & 42565 & 4895 & 17266 & 1009 & 3792 & 12748 & 5337 \\
\hline Number of PID & 922 & 8270 & 11891 & 2453 & 4170 & 717 & 1554 & 3240 & 1416 \\
\hline R-squared & 0.11 & 0.03 & 0.06 & & 0.01 & & 0.04 & 0.01 & 0.01 \\
\hline
\end{tabular}


Table 7. b. Effects of Benefits on Relative Deprivation in Satisfaction (8 Cohorts)

\begin{tabular}{|c|c|c|c|c|c|c|c|c|c|}
\hline Variables (8) & PrivTr & $\begin{array}{l}\text { PubTr } \\
\end{array}$ & Taxes & UnempTr & RetWidTr & MatTr & IllTr & RetTr & WidTr \\
\hline \multirow{2}{*}{ Transfer (i) } & 2.2450 & -1.4771 & -0.1533 & -1.0057 & -1.9510 & -4.0524 & -3.4290 & -2.2030 & -1.0803 \\
\hline & [3.7458] & {$[0.3012]^{* * *}$} & {$[0.0481]^{* * *}$} & {$[0.4535]^{* *}$} & {$[0.4549] * * *$} & [2.1934]* & {$[1.0421]^{* * *}$} & {$[0.5787]^{* * *}$} & [1.0907] \\
\hline \multirow{2}{*}{$\operatorname{Transfer}^{2}$ (i) } & -11.9161 & 0.6723 & & 0.4125 & 2.8967 & -13.2464 & -2.1812 & 5.5786 & 1.1530 \\
\hline & [15.0695] & {$[0.1975]^{* * *}$} & & [0.2279]* & {$[1.0336] * * *$} & [13.6273] & [6.9637] & {$[1.4662] * * *$} & [1.2019] \\
\hline \multirow{2}{*}{ Age } & 0.0304 & -0.0641 & -0.0256 & 0.0177 & -0.0435 & 0.0076 & 0.0203 & -0.0778 & -0.0287 \\
\hline & {$[0.0562]$} & {$[0.0085]^{* * *}$} & {$[0.0048]^{* * *}$} & {$[0.0060]^{* * *}$} & {$[0.0188]^{* *}$} & {$[0.0100]$} & {$[0.0053]^{* * *}$} & {$[0.0312]^{* *}$} & [0.0237] \\
\hline \multirow{2}{*}{$\mathrm{Age}^{2} / 100$} & -0.0494 & 0.0319 & -0.0031 & -0.0216 & 0.0188 & -0.0122 & -0.0212 & 0.0425 & 0.0049 \\
\hline & {$[0.0644]$} & {$[0.0064]^{* * *}$} & [0.0053] & {$[0.0072]^{* * *}$} & [0.0131] & [0.0115] & {$[0.0051]^{* * *}$} & {$[0.0216]^{* *}$} & {$[0.0166]$} \\
\hline \multirow{2}{*}{ FamSize } & -0.0288 & 0.0058 & 0.0227 & 0.0127 & 0.0034 & -0.0024 & 0.0047 & 0.0109 & 0.0020 \\
\hline & {$[0.0891]$} & {$[0.0081]$} & {$[0.0051]^{* * *}$} & {$[0.0073]^{*}$} & [0.0109] & {$[0.0152]$} & {$[0.0086]$} & {$[0.0144]$} & {$[0.0166]$} \\
\hline \multirow{2}{*}{ HouseOwnership } & -0.0592 & -0.0007 & -0.0147 & -0.0695 & 0.0359 & -0.1004 & -0.1149 & 0.0692 & -0.0099 \\
\hline & [0.1485] & [0.0194] & {$[0.0126]$} & {$[0.0199]^{* * *}$} & [0.0258] & {$[0.0368]^{* * *}$} & {$[0.0295]^{* * *}$} & {$[0.0316]^{* *}$} & {$[0.0450]$} \\
\hline \multirow{2}{*}{ Married } & 0.2039 & -0.0931 & -0.0626 & -0.0715 & -0.1256 & -0.1186 & -0.0212 & -0.0984 & 0.0000 \\
\hline & [0.1848] & {$[0.0329]^{* * *}$} & {$[0.0181]^{* * *}$} & {$[0.0215]^{* * *}$} & {$[0.0471]^{* * *}$} & {$[0.0444]^{* * *}$} & {$[0.0274]$} & {$[0.0502]^{* *}$} & [0.0000] \\
\hline \multirow{2}{*}{ Unemployed } & 0.1768 & 0.1166 & 0.1629 & 0.1770 & -0.0807 & 0.2039 & 0.1125 & -0.2170 & -0.0554 \\
\hline & [0.1103] & {$[0.0216]^{* * *}$} & {$[0.0149]^{* * *}$} & {$[0.0219]^{* * *}$} & [0.0774] & {$[0.0453] * * *$} & [0.0681]* & [0.1877] & [0.0866] \\
\hline \multirow{2}{*}{ IncomeSource } & 0.0070 & 0.0102 & 0.0015 & 0.0192 & -0.0049 & 0.0239 & 0.0265 & 0.0065 & -0.0221 \\
\hline & {$[0.0226]$} & {$[0.0048]^{* *}$} & {$[0.0032]$} & {$[0.0058]^{* * *}$} & [0.0136] & {$[0.0108]^{* *}$} & {$[0.0101]^{* * *}$} & {$[0.0184]$} & [0.0215] \\
\hline \multirow{2}{*}{ SeconEduc } & 0.0528 & 0.0263 & -0.0077 & -0.0683 & 0.0246 & -0.1246 & -0.0409 & 0.0145 & 0.0284 \\
\hline & {$[0.1746]$} & {$[0.0286]$} & [0.0143] & {$[0.0245]^{* * *}$} & [0.0364] & {$[0.0539]^{* *}$} & {$[0.0451]$} & [0.0396] & [0.0837] \\
\hline \multirow{2}{*}{ HighEduc } & 0.1211 & -0.0201 & -0.0065 & -0.1507 & -0.0312 & -0.2150 & 0.0164 & -0.0345 & -0.1284 \\
\hline & [0.3045] & {$[0.0412]$} & {$[0.0195]$} & {$[0.0273]^{* * *}$} & {$[0.0561]$} & {$[0.0655]^{* * *}$} & {$[0.0534]$} & {$[0.0610]$} & [0.1315] \\
\hline \multirow{2}{*}{ Children $<16$} & -0.1029 & -0.0147 & -0.0011 & 0.0226 & -0.0033 & 0.0628 & 0.0564 & -0.0058 & -0.0200 \\
\hline & [0.0959] & {$[0.0138]$} & {$[0.0074]$} & [0.0116]* & [0.0223] & {$[0.0213]^{* * *}$} & {$[0.0173]^{* * *}$} & [0.0303] & [0.0322] \\
\hline \multirow{2}{*}{ Illness } & -0.0182 & 0.0463 & 0.0320 & 0.0782 & 0.0450 & 0.1549 & 0.0761 & 0.0422 & 0.0542 \\
\hline & [0.1133] & {$[0.0101]^{* * *}$} & {$[0.0102]^{* * *}$} & {$[0.0238]^{* * *}$} & {$[0.0116]^{* * *}$} & {$[0.0488] * * *$} & {$[0.0287]^{* * *}$} & {$[0.0138]^{* * *}$} & {$[0.0207]^{* * *}$} \\
\hline \multirow{2}{*}{ PublicSector } & 0.2677 & 0.0669 & -0.0454 & -0.0297 & 0.1718 & -0.0421 & -0.0469 & 1.3852 & 0.1637 \\
\hline & {$[0.2558]$} & [0.0407] & {$[0.0166]^{* * *}$} & [0.0353] & [0.1131] & [0.0641] & {$[0.0783]$} & {$[0.3425]^{* * *}$} & [0.1092] \\
\hline \multirow{2}{*}{ ServiceSector } & 0.0727 & -0.0161 & -0.0154 & -0.0310 & -0.0267 & -0.0399 & -0.0009 & -0.1793 & 0.0535 \\
\hline & {$[0.1318]$} & [0.0262] & {$[0.0118]$} & [0.0230] & [0.0630] & [0.0495] & {$[0.0441]$} & [0.1387] & {$[0.0726]$} \\
\hline \multirow{2}{*}{ FullTime } & -0.2402 & -0.2254 & -0.1443 & -0.1534 & -0.2052 & -0.2004 & -0.1851 & -0.0062 & -0.2903 \\
\hline & [0.1277]* & {$[0.0243]^{* * *}$} & {$[0.0129]^{* * *}$} & {$[0.0233]^{* * *}$} & {$[0.0697]^{* * *}$} & {$[0.0497]^{* * *}$} & {$[0.0382]^{* * *}$} & [0.1391] & {$[0.0746]^{* * *}$} \\
\hline \multirow{2}{*}{ Constant } & 1.6867 & 4.2649 & 2.6777 & 1.3145 & 3.7507 & 1.7228 & 1.2220 & 4.8807 & 3.4731 \\
\hline & [1.2918] & {$[0.2788]^{* * *}$} & {$[0.1090]^{* * *}$} & {$[0.1202]^{* * *}$} & {$[0.6789]^{* * *}$} & {$[0.2267] * * *$} & {$[0.1412]^{* * *}$} & {$[1.1328]^{* * *}$} & {$[0.8617]^{* * *}$} \\
\hline \multirow{2}{*}{$\mathrm{F}$} & 0.81 & 19.37 & 52.03 & 860.31 & 4.65 & 568.86 & 271.94 & 4.14 & 2.78 \\
\hline & 0.7462 & {$[0.0000]$} & {$[0.0000]$} & {$[0.0000]$} & {$[0.0000]$} & {$[0.0000]$} & {$[0.0000]$} & {$[0.0000]$} & {$[0.0000]$} \\
\hline \multirow{2}{*}{ LM } & 67.14 & 4305.21 & 6048.88 & 191.47 & 2988.09 & 14.84 & 355.64 & 2154.02 & 909.65 \\
\hline & {$[0.0000]$} & {$[0.0000]$} & {$[0.0000]$} & {$[0.0000]$} & {$[0.0000]$} & 0.0001 & {$[0.0000]$} & {$[0.0000]$} & {$[0.0000]$} \\
\hline \multirow{2}{*}{ Hausman } & 294.92 & 237.17 & 124.91 & & 232.60 & 29.45 & 26.23 & 320.32 & 99.88 \\
\hline & {$[0.0000]$} & {$[0.0000]$} & {$[0.0000]$} & & {$[0.0000]$} & 0.2037 & 0.5602 & {$[0.0000]$} & {$[0.0000]$} \\
\hline Observations & 1325 & 27777 & 42584 & 4895 & 17276 & 1009 & 3794 & 12755 & 5341 \\
\hline Number of PID & 922 & 8274 & 11895 & 2453 & 4172 & 717 & 1554 & 3241 & 1418 \\
\hline R-squared & 0.10 & 0.03 & 0.05 & & 0.01 & & & 0.01 & 0.02 \\
\hline
\end{tabular}


Table 7. c. Effects of Benefits on Relative Deprivation in Satisfaction (24 Cohorts)

\begin{tabular}{|c|c|c|c|c|c|c|c|c|c|}
\hline Variables (24) & PrivTr & PubTr & Taxes & UnempTr & RetWidTr & MatTr & IllTr & RetTr & WidTr \\
\hline \multirow{2}{*}{ Transfer (i) } & 2.9510 & -1.4872 & -0.1674 & -0.8168 & -2.0318 & -4.0469 & -3.0628 & -2.2703 & -1.2208 \\
\hline & [4.2459] & {$[0.3077]^{* * *}$} & {$[0.0512]^{* * *}$} & {$[0.4665]^{*}$} & {$[0.4677]^{* * *}$} & {$[2.2101]^{*}$} & {$[1.0467]^{* * *}$} & {$[0.5908]^{* * *}$} & [1.0969] \\
\hline \multirow{2}{*}{$\operatorname{Transfer}^{2}$ (i) } & -15.3824 & 0.6120 & & 0.3241 & 2.8985 & -14.7058 & -3.4740 & 5.5087 & 1.2538 \\
\hline & [17.4122] & {$[0.2024] * * *$} & & {$[0.2312]$} & {$[1.0197]^{* * *}$} & [13.5473] & [7.2168] & {$[1.4906]^{* * *}$} & [1.2091] \\
\hline \multirow{2}{*}{ Age } & 0.0272 & -0.0644 & -0.0262 & 0.0115 & -0.0480 & 0.0032 & 0.0176 & -0.0745 & -0.0382 \\
\hline & [0.0583] & {$[0.0082]^{* * *}$} & {$[0.0048]^{* * *}$} & [0.0059]* & {$[0.0184]^{* * *}$} & [0.0099] & {$[0.0052]^{* * *}$} & {$[0.0308]^{* *}$} & {$[0.0232]^{*}$} \\
\hline \multirow{2}{*}{$\mathrm{Age}^{2} / 100$} & -0.0434 & 0.0325 & -0.0019 & -0.0138 & 0.0222 & -0.0067 & -0.0177 & 0.0406 & 0.0115 \\
\hline & {$[0.0656]$} & {$[0.0062]^{* * *}$} & {$[0.0053]$} & [0.0071]* & [0.0128]* & [0.0114] & {$[0.0050]^{* * *}$} & {$[0.0213]^{*}$} & {$[0.0162]$} \\
\hline \multirow{2}{*}{ FamSize } & -0.0307 & 0.0062 & 0.0237 & 0.0112 & 0.0030 & -0.0031 & 0.0041 & 0.0104 & 0.0016 \\
\hline & [0.0941] & {$[0.0078]$} & {$[0.0051]^{* * *}$} & {$[0.0072]$} & {$[0.0108]$} & {$[0.0145]$} & {$[0.0083]$} & {$[0.0142]$} & {$[0.0162]$} \\
\hline \multirow{2}{*}{ HouseOwnership } & -0.0436 & -0.0006 & -0.0136 & -0.0643 & 0.0350 & -0.1042 & -0.1115 & 0.0670 & -0.0133 \\
\hline & [0.1623] & [0.0189] & {$[0.0125]$} & {$[0.0195]^{* * *}$} & {$[0.0254]$} & {$[0.0354]^{* * *}$} & {$[0.0285]^{* * *}$} & {$[0.0314]^{* *}$} & {$[0.0442]$} \\
\hline \multirow{2}{*}{ Married } & 0.1719 & -0.0943 & -0.0640 & -0.0674 & -0.1245 & -0.1149 & -0.0223 & -0.0964 & 0.0000 \\
\hline & {$[0.1936]$} & {$[0.0323]^{* * *}$} & {$[0.0181]^{* * *}$} & {$[0.0215]^{* * *}$} & {$[0.0464]^{* * *}$} & {$[0.0426]^{* * *}$} & {$[0.0266]$} & {$[0.0490]^{* *}$} & [0.0000] \\
\hline \multirow{2}{*}{ Unemployed } & 0.1650 & 0.1087 & 0.1593 & 0.1680 & -0.0767 & 0.2002 & 0.1162 & -0.1705 & -0.0522 \\
\hline & [0.1154] & {$[0.0209]^{* * *}$} & {$[0.0147]^{* * *}$} & {$[0.0213]^{* * *}$} & {$[0.0707]$} & {$[0.0439] * * *$} & [0.0659]* & [0.1828] & [0.0795] \\
\hline \multirow{2}{*}{ IncomeSource } & 0.0120 & 0.0092 & 0.0015 & 0.0163 & -0.0053 & 0.0239 & 0.0256 & 0.0030 & -0.0212 \\
\hline & {$[0.0239]$} & [0.0047]* & {$[0.0032]$} & {$[0.0056]^{* * *}$} & {$[0.0137]$} & {$[0.0105]^{* *}$} & {$[0.0097]^{* * *}$} & {$[0.0186]$} & [0.0217] \\
\hline \multirow{2}{*}{ SeconEduc } & 0.1988 & 0.1407 & 0.0562 & 0.0337 & 0.1592 & -0.0092 & 0.0436 & 0.1483 & 0.1866 \\
\hline & [0.1799] & {$[0.0317]^{* * *}$} & {$[0.0146]^{* * *}$} & [0.0268] & {$[0.0420]^{* * *}$} & {$[0.0582]$} & {$[0.0521]$} & {$[0.0457]^{* * *}$} & [0.0988]* \\
\hline \multirow{2}{*}{ HighEduc } & 0.4436 & 0.1397 & 0.0915 & 0.0004 & 0.1264 & -0.0830 & 0.1754 & 0.1272 & -0.0066 \\
\hline & {$[0.3547]$} & {$[0.0461]^{* * *}$} & {$[0.0207]^{* * *}$} & {$[0.0328]$} & {$[0.0630]^{* *}$} & {$[0.0789]$} & {$[0.0684]^{* *}$} & {$[0.0680] *$} & [0.1568] \\
\hline \multirow{2}{*}{ Children $<16$} & -0.1174 & -0.0143 & 0.0001 & 0.0225 & 0.0000 & 0.0587 & 0.0508 & -0.0036 & -0.0158 \\
\hline & [0.0981] & {$[0.0133]$} & {$[0.0073]$} & {$[0.0114]^{* *}$} & {$[0.0219]$} & {$[0.0203]^{* * *}$} & {$[0.0165]^{* * *}$} & [0.0295] & [0.0317] \\
\hline \multirow{2}{*}{ Illness } & -0.0404 & 0.0438 & 0.0306 & 0.0734 & 0.0435 & 0.1419 & 0.0730 & 0.0414 & 0.0505 \\
\hline & [0.1194] & {$[0.0099]^{* * *}$} & {$[0.0101]^{* * *}$} & {$[0.0227]^{* * *}$} & {$[0.0114]^{* * *}$} & {$[0.0470] * * *$} & {$[0.0279]^{* * *}$} & {$[0.0136]^{* * *}$} & {$[0.0204]^{* *}$} \\
\hline \multirow{2}{*}{ PublicSector } & 0.3134 & 0.0678 & -0.0494 & -0.0324 & 0.2076 & -0.0586 & -0.0541 & 1.2633 & 0.2079 \\
\hline & {$[0.2801]$} & {$[0.0405]^{*}$} & {$[0.0171] * * *$} & {$[0.0351]$} & [0.1163]* & [0.0649] & {$[0.0821]$} & {$[0.3298]^{* * *}$} & [0.1164]* \\
\hline \multirow{2}{*}{ ServiceSector } & 0.0360 & -0.0231 & -0.0188 & -0.0365 & -0.0486 & -0.0421 & -0.0028 & -0.2259 & 0.0434 \\
\hline & {$[0.1381]$} & {$[0.0254]$} & {$[0.0118]$} & {$[0.0224]$} & {$[0.0630]$} & [0.0474] & {$[0.0424]$} & {$[0.1466]$} & {$[0.0704]$} \\
\hline \multirow{2}{*}{ FullTime } & -0.2319 & -0.2159 & -0.1431 & -0.1460 & -0.1838 & -0.1803 & -0.1729 & -0.0029 & -0.2651 \\
\hline & {$[0.1320]^{*}$} & {$[0.0232]^{* * *}$} & {$[0.0128]^{* * *}$} & {$[0.0226]^{* * *}$} & {$[0.0696]^{* * *}$} & {$[0.0481]^{* * *}$} & {$[0.0363]^{* * *}$} & {$[0.1425]$} & {$[0.0713]^{* * *}$} \\
\hline \multirow{2}{*}{ Constant } & 1.6023 & 4.2157 & 2.6250 & 1.3575 & 3.8757 & 1.7197 & 1.2020 & 4.7308 & 3.7732 \\
\hline & [1.3645] & {$[0.2689] * * *$} & {$[0.1087]^{* * *}$} & {$[0.1181]^{* * *}$} & {$[0.6669] * * *$} & {$[0.2238] * * *$} & {$[0.1377]^{* * *}$} & {$[1.1190]^{* * *}$} & {$[0.8439] * * *$} \\
\hline \multirow{2}{*}{$\mathrm{F}$} & 0.93 & 13.68 & 33.04 & 1090.91 & 4.77 & 814.45 & 540.34 & 3.62 & 3.14 \\
\hline & 0.5861 & {$[0.0000]$} & {$[0.0000]$} & {$[0.0000]$} & {$[0.0000]$} & {$[0.0000]$} & {$[0.0000]$} & {$[0.0000]$} & {$[0.0000]$} \\
\hline \multirow{2}{*}{ LM } & 73.42 & 4236.34 & 6167.93 & 180.82 & 2921.82 & 12.56 & 347.25 & 2152.18 & 881.02 \\
\hline & {$[0.0000]$} & {$[0.0000]$} & {$[0.0000]$} & {$[0.0000]$} & {$[0.0000]$} & {$[0.0000]$} & {$[0.0000]$} & {$[0.0000]$} & {$[0.0000]$} \\
\hline \multirow{2}{*}{ Hausman } & & 241.43 & 140.62 & & 135.12 & 21.16 & 46.90 & 150.71 & 52.72 \\
\hline & & {$[0.0000]$} & {$[0.0000]$} & & {$[0.0000]$} & 0.8532 & 0.2432 & {$[0.0000]$} & 0.0452 \\
\hline Observations & 1325 & 27760 & 42565 & 4895 & 17266 & 1009 & 3792 & 12748 & 5337 \\
\hline Number of PID & 922 & 8270 & 11891 & 2453 & 4170 & 717 & 1554 & 3240 & 1416 \\
\hline R-squared & 0.13 & 0.03 & 0.05 & & 0.01 & & & 0.01 & 0.02 \\
\hline
\end{tabular}


Table 8.a. Income Satisfaction

\begin{tabular}{|c|c|c|c|c|c|c|c|c|c|}
\hline \multirow{2}{*}{ Variables } & \multicolumn{3}{|c|}{ Satisfaction Deprivation } & \multicolumn{3}{|c|}{ Net Individual Income Deprivation } & \multicolumn{3}{|c|}{ Gross Individual Income Deprivation } \\
\hline & 6 Cohorts & 8 Cohorts & 24 Cohorts & 6 Cohorts & 8 Cohorts & 24 Cohorts & 6 Cohorts & 8 Cohorts & 24 Cohorts \\
\hline \multirow[b]{2}{*}{ Age } & -0.1149 & -0.0843 & -0.0851 & -0.0235 & -0.0281 & -0.0239 & -0.0240 & -0.0290 & -0.0248 \\
\hline & {$[0.0122]^{* * *}$} & {$[0.0077]^{* * *}$} & {$[0.0079] * * *$} & {$[0.0025]^{* * *}$} & {$[0.0028]^{* * *}$} & {$[0.0026]^{* * *}$} & {$[0.0025]^{* * *}$} & {$[0.0027]^{* * *}$} & {$[0.0026]^{* * *}$} \\
\hline \multirow{2}{*}{$\mathrm{Age}^{2} / 100$} & 0.0739 & 0.0520 & 0.0528 & 0.0332 & 0.0378 & 0.0336 & 0.0336 & 0.0385 & 0.0343 \\
\hline & {$[0.0059] * * *$} & {$[0.0034]^{* * *}$} & {$[0.0035]^{* * *}$} & {$[0.0025]^{* * *}$} & {$[0.0027]^{* * *}$} & {$[0.0026] * * *$} & {$[0.0025]^{* * *}$} & {$[0.0027] * * *$} & {$[0.0026]^{* * *}$} \\
\hline \multirow{2}{*}{ Male } & 0.0240 & 0.0183 & 0.0234 & 0.0241 & 0.0006 & 0.0275 & 0.0176 & 0.0041 & 0.0229 \\
\hline & [0.0161] & [0.0162] & [0.0161] & [0.0188] & [0.0177] & [0.0169] & [0.0177] & [0.0171] & [0.0167] \\
\hline \multirow{2}{*}{ FamSize } & 0.0068 & 0.0007 & 0.0030 & -0.0187 & -0.0205 & -0.0186 & -0.0195 & -0.0220 & -0.0191 \\
\hline & {$[0.0063]$} & {$[0.0057]$} & [0.0059] & {$[0.0052] * * *$} & {$[0.0052] * * *$} & {$[0.0052] * * *$} & {$[0.0052] * * *$} & {$[0.0052]^{* * *}$} & {$[0.0052]^{* * *}$} \\
\hline \multirow{2}{*}{ HouseOwnership } & 0.1741 & 0.1750 & 0.1770 & 0.1808 & 0.1804 & 0.1811 & 0.1812 & 0.1815 & 0.1812 \\
\hline & {$[0.0174]^{* * *}$} & {$[0.0173]^{* * *}$} & {$[0.0173]^{* * *}$} & {$[0.0174]^{* * *}$} & {$[0.0173]^{* * *}$} & {$[0.0174]^{* * *}$} & {$[0.0174]^{* * *}$} & {$[0.0173]^{* * *}$} & {$[0.0174]^{* * *}$} \\
\hline \multirow{2}{*}{ Married } & 0.0138 & 0.0292 & 0.0264 & 0.1815 & 0.1819 & 0.1811 & 0.1815 & 0.1807 & 0.1816 \\
\hline & [0.0278] & [0.0249] & {$[0.0255]$} & {$[0.0169]^{* * *}$} & {$[0.0168]^{* * *}$} & {$[0.0169] * * *$} & {$[0.0169] * * *$} & {$[0.0169] * * *$} & {$[0.0169]^{* * *}$} \\
\hline \multirow{2}{*}{ Unemployed } & -0.2363 & -0.3061 & -0.3103 & -0.6284 & -0.6312 & -0.6280 & -0.6300 & -0.6340 & -0.6293 \\
\hline & {$[0.0579]^{* * *}$} & {$[0.0467]^{* * *}$} & {$[0.0470]^{* * *}$} & {$[0.0259]^{* * *}$} & {$[0.0258]^{* * *}$} & {$[0.0259]^{* * *}$} & {$[0.0259]^{* * *}$} & {$[0.0259]^{* * *}$} & {$[0.0259]^{* * *}$} \\
\hline \multirow{2}{*}{ IncomeSource } & 0.0153 & 0.0137 & 0.0135 & 0.0006 & -0.0024 & 0.0008 & 0.0003 & 0.0002 & 0.0004 \\
\hline & {$[0.0052]^{* * *}$} & {$[0.0051]^{* * *}$} & {$[0.0051]^{* * *}$} & [0.0048] & [0.0048] & [0.0048] & {$[0.0047]$} & {$[0.0047]$} & {$[0.0047]$} \\
\hline \multirow{2}{*}{ SeconEduc } & 0.2456 & 0.1399 & 0.2752 & 0.1422 & 0.1457 & 0.1461 & 0.1284 & 0.1412 & 0.1386 \\
\hline & {$[0.0219]^{* * *}$} & {$[0.0189]^{* * *}$} & {$[0.0235]^{* * *}$} & {$[0.0203]^{* * *}$} & {$[0.0188]^{* * *}$} & {$[0.0193]^{* * *}$} & {$[0.0198]^{* * *}$} & {$[0.0188]^{* * *}$} & {$[0.0194]^{* * *}$} \\
\hline \multirow{2}{*}{ HighEduc } & 0.4973 & 0.2689 & 0.4688 & 0.2628 & 0.2706 & 0.2678 & 0.2375 & 0.2589 & 0.2503 \\
\hline & {$[0.0337]^{* * *}$} & {$[0.0211]^{* * *}$} & {$[0.0298]^{* * *}$} & {$[0.0314]^{* * *}$} & {$[0.0209]^{* * *}$} & {$[0.0235]^{* * *}$} & {$[0.0302]^{* * *}$} & {$[0.0208]^{* * *}$} & {$[0.0243]^{* * *}$} \\
\hline \multirow{2}{*}{ Children $<16$} & -0.0233 & -0.0320 & -0.0313 & -0.0325 & -0.0350 & -0.0334 & -0.0341 & -0.0381 & -0.0346 \\
\hline & {$[0.0094]^{* *}$} & {$[0.0093]^{* * *}$} & {$[0.0093]^{* * *}$} & {$[0.0094]^{* * *}$} & {$[0.0094]^{* * *}$} & {$[0.0094]^{* * *}$} & {$[0.0094]^{* * *}$} & {$[0.0094]^{* * *}$} & {$[0.0094]^{* * *}$} \\
\hline \multirow{2}{*}{ Illness } & -0.0528 & -0.0522 & -0.0538 & -0.1172 & -0.1185 & -0.1173 & -0.1164 & -0.1174 & -0.1171 \\
\hline & {$[0.0160]^{* * *}$} & {$[0.0157]^{* * *}$} & {$[0.0157] * * *$} & {$[0.0137]^{* * *}$} & {$[0.0137] * * *$} & {$[0.0137]^{* * *}$} & {$[0.0137]^{* * *}$} & {$[0.0137]^{* * *}$} & {$[0.0137]^{* * *}$} \\
\hline PublicSector & $\begin{array}{c}0.0424 \\
{[0.0280]}\end{array}$ & $\begin{array}{c}0.0731 \\
{[0.0256]^{* * *}}\end{array}$ & $\begin{array}{c}0.0643 \\
{[0.0263]^{* *}}\end{array}$ & $\begin{array}{c}0.1539 \\
{[0.0236]^{* * *}}\end{array}$ & $\begin{array}{c}0.1543 \\
{[0.0235]^{* * *}}\end{array}$ & $\begin{array}{c}0.1541 \\
{[0.0236]^{* * *}}\end{array}$ & $\begin{array}{c}0.1512 \\
{[0.0235]^{* * *}}\end{array}$ & $\begin{array}{c}0.1458 \\
{[0.0235]^{* * *}}\end{array}$ & $\begin{array}{c}0.1523 \\
{[0.0235]^{* * *}}\end{array}$ \\
\hline \multirow{2}{*}{ FullTime } & 0.0663 & 0.0944 & 0.0962 & 0.3296 & 0.3319 & 0.3300 & 0.3277 & 0.3247 & 0.3287 \\
\hline & {$[0.0422]$} & {$[0.0370]^{* *}$} & {$[0.0376]^{* *}$} & {$[0.0242]^{* * *}$} & {$[0.0242]^{* * *}$} & {$[0.0242]^{* * *}$} & {$[0.0242]^{* * *}$} & {$[0.0242] * * *$} & {$[0.0242]^{* * *}$} \\
\hline \multirow{2}{*}{ Dummy PrivTransf } & -0.2178 & -0.2393 & -0.2373 & -0.2863 & -0.2899 & -0.2868 & -0.2874 & -0.2931 & -0.2876 \\
\hline & {$[0.0428]^{* * * *}$} & {$[0.0423]^{* * *}$} & {$[0.0423]^{* * *}$} & {$[0.0418]^{* * *}$} & {$[0.0418]^{* * *}$} & {$[0.0418]^{* * *}$} & {$[0.0418]^{* * *}$} & {$[0.0418]^{* * *}$} & {$[0.0418]^{* * *}$} \\
\hline \multirow{2}{*}{ Dummy PubTransf } & -0.1184 & -0.1040 & -0.1028 & -0.0666 & -0.0626 & -0.0677 & -0.0658 & -0.0630 & -0.0666 \\
\hline & {$[0.0182]^{* * *}$} & {$[0.0175]^{* * *}$} & {$[0.0175]^{* * *}$} & {$[0.0171]^{* * *}$} & {$[0.0171]^{* * *}$} & {$[0.0171]^{* * *}$} & {$[0.0171]^{* * *}$} & {$[0.0170]^{* * *}$} & {$[0.0171]^{* * *}$} \\
\hline \multirow{2}{*}{ Dummy Taxes ${ }^{\mathrm{i}}$} & -0.1440 & -0.1377 & -0.1430 & -0.0893 & -0.0919 & -0.0896 & -0.0886 & -0.0905 & -0.0893 \\
\hline & {$[0.0219]^{* * *}$} & {$[0.0217]^{* * *}$} & {$[0.0218]^{* * *}$} & {$[0.0209]^{* * *}$} & {$[0.0208]^{* * *}$} & {$[0.0208]^{* * *}$} & {$[0.0208]^{* * *}$} & {$[0.0208]^{* * *}$} & {$[0.0208]^{* * *}$} \\
\hline & 0.5227 & 0.5348 & 0.5340 & 0.6316 & 0.6153 & 0.6262 & 0.6143 & 0.5831 & 0.6194 \\
\hline EqNetHousInc & {$[0.0259]^{* * *}$} & {$[0.0261]^{* * *}$} & {$[0.0256]^{* * *}$} & {$[0.0259]^{* * *}$} & {$[0.0259]^{* * *}$} & {$[0.0255]^{* * *}$} & {$[0.0267]^{* * *}$} & {$[0.0269]^{* * *}$} & {$[0.0262]^{* * *}$} \\
\hline Dopriyation & -2.0124 & -1.7815 & -1.7985 & 0.6582 & 2.3770 & 0.1806 & 0.7617 & 1.3257 & 0.3665 \\
\hline Deprivation & {$[0.2619]^{* * *}$} & {$[0.2126]^{* * *}$} & {$[0.2187]^{* * *}$} & {$[0.4341]$} & {$[0.5129]^{* * *}$} & [0.3174] & {$[0.2007]^{* * *}$} & {$[0.2179] * * *$} & {$[0.1608]^{* *}$} \\
\hline Deprivation $^{2}$ & & & & -1.9583 & -3.8229 & -0.4455 & -0.4066 & -0.6156 & -0.1231 \\
\hline & & & & {$[0.3585]^{* * *}$} & {$[0.8979]^{* * *}$} & {$[0.2437]^{*}$} & {$[0.0734]^{* * *}$} & {$[0.1657] * * *$} & {$[0.0465]^{* * *}$} \\
\hline Intra-group Variance & & & & $\begin{array}{c}-0.7329 \\
{[2.6292]}\end{array}$ & $\begin{array}{c}-1.3475 \\
{[3.1173]}\end{array}$ & $\begin{array}{c}0.5693 \\
{[1.3955]}\end{array}$ & $\begin{array}{c}-0.8715 \\
{[0.4308]^{* *}}\end{array}$ & $\begin{array}{c}-0.9305 \\
{[0.4981]^{*}}\end{array}$ & $\begin{array}{c}-0.1980 \\
{[0.2202]}\end{array}$ \\
\hline Log Likelihood & -96369.001 & -96416.781 & -96371.739 & -96434.536 & -96464.345 & -96441.157 & -96430.147 & -96447.866 & -96438.589 \\
\hline Rho & 0.4403 & 0.4409 & 0.4416 & 0.4466 & 0.4450 & 0.4471 & 0.4457 & 0.4430 & 0.4465 \\
\hline & $(0.0112)$ & $(0.0112)$ & $(0.0112)$ & $(0.0112)$ & $(0.0112)$ & $(0.0112)$ & $(0.0112)$ & $(0.0111)$ & $(0.0112)$ \\
\hline & $\mathrm{P}=53715$ & $\mathrm{P}=53697$ & $\mathrm{P}=53901$ & & & & & & \\
\hline Number of Observations & 62852 & 62878 & 62852 & 62852 & 62878 & 62852 & 62852 & 62878 & 62852 \\
\hline
\end{tabular}


Table 8.b Income Satisfaction (Public Transfers Instrumented)

\begin{tabular}{|c|c|c|c|c|c|c|c|c|c|}
\hline \multirow{2}{*}{ Variables } & \multicolumn{3}{|c|}{ Satisfaction Deprivation } & \multicolumn{3}{|c|}{ Net Individual Income Deprivation } & \multicolumn{3}{|c|}{ Gross Individual Income Deprivation } \\
\hline & 6 Cohorts & 8 Cohorts & 24 Cohorts & 6 Cohorts & 8 Cohorts & 24 Cohorts & 6 Cohorts & 8 Cohorts & 24 Cohorts \\
\hline \multirow[b]{2}{*}{ Age } & -0.1149 & -0.0748 & -0.0769 & -0.0236 & -0.0269 & -0.0226 & -0.0240 & -0.0276 & -0.0233 \\
\hline & {$[0.0119]^{* * *}$} & {$[0.0077]^{* * *}$} & {$[0.0078]^{* * *}$} & {$[0.0025]^{* * *}$} & {$[0.0028]^{* * *}$} & {$[0.0026]^{* * *}$} & {$[0.0025]^{* * *}$} & {$[0.0028]^{* * *}$} & {$[0.0026]^{* * *}$} \\
\hline \multirow{2}{*}{ Age $^{2} / 100$} & 0.0741 & 0.0459 & 0.0476 & 0.0335 & 0.0337 & 0.0300 & 0.0339 & 0.0341 & 0.0306 \\
\hline & {$[0.0058]^{* * *}$} & {$[0.0036]^{* * *}$} & {$[0.0036]^{* * *}$} & {$[0.0025]^{* * *}$} & {$[0.0029]^{* * *}$} & {$[0.0027]^{* * *}$} & {$[0.0025]^{* * *}$} & {$[0.0028]^{* * *}$} & {$[0.0027]^{* * *}$} \\
\hline \multirow{2}{*}{ Male } & 0.0375 & -0.0024 & 0.0043 & 0.0360 & -0.0398 & -0.0010 & 0.0285 & -0.0344 & -0.0050 \\
\hline & {$[0.0163]^{* *}$} & [0.0167] & [0.0167] & [0.0190]* & {$[0.0188]^{* *}$} & [0.0177] & [0.0178] & [0.0181]* & [0.0175] \\
\hline \multirow{2}{*}{ FamSize } & 0.0063 & 0.0021 & 0.0041 & -0.0192 & -0.0163 & -0.0150 & -0.0200 & -0.0177 & -0.0154 \\
\hline & {$[0.0062]$} & {$[0.0058]$} & {$[0.0059]$} & {$[0.0052]^{* * *}$} & {$[0.0052]^{* * *}$} & {$[0.0052]^{* * *}$} & {$[0.0052]^{* * *}$} & {$[0.0053]^{* * *}$} & {$[0.0053]^{* * *}$} \\
\hline \multirow{2}{*}{ HouseOwnership } & 0.1741 & 0.1779 & 0.1795 & 0.1806 & 0.1818 & 0.1828 & 0.1810 & 0.1831 & 0.1828 \\
\hline & {$[0.0173]^{* * *}$} & {$[0.0174]^{* * *}$} & {$[0.0174]^{* * *}$} & {$[0.0174]^{* * *}$} & {$[0.0174]^{* * *}$} & {$[0.0174]^{* * *}$} & {$[0.0174]^{* * *}$} & {$[0.0174]^{* * *}$} & {$[0.0174]^{* * *}$} \\
\hline \multirow{2}{*}{ Married } & 0.0154 & 0.0530 & 0.0480 & 0.1817 & 0.1830 & 0.1834 & 0.1818 & 0.1817 & 0.1836 \\
\hline & {$[0.0273]$} & {$[0.0245]^{* *}$} & {$[0.0250]^{*}$} & {$[0.0168]^{* * *}$} & {$[0.0169]^{* * *}$} & {$[0.0169]^{* * *}$} & {$[0.0168]^{* * *}$} & {$[0.0169]^{* * *}$} & {$[0.0169]^{* * *}$} \\
\hline \multirow{2}{*}{ Unemployed } & -0.2392 & -0.3473 & -0.3468 & -0.6292 & -0.6220 & -0.6227 & -0.6308 & -0.6245 & -0.6235 \\
\hline & {$[0.0568]^{* * *}$} & {$[0.0457]^{* * *}$} & {$[0.0458]^{* * *}$} & {$[0.0258]^{* * *}$} & {$[0.0260]^{* * *}$} & {$[0.0260]^{* * *}$} & {$[0.0259]^{* * *}$} & {$[0.0260]^{* * *}$} & {$[0.0260]^{* * *}$} \\
\hline \multirow{2}{*}{ IncomeSource } & 0.0153 & 0.0132 & 0.0130 & 0.0007 & -0.0013 & 0.0015 & 0.0004 & 0.0018 & 0.0015 \\
\hline & {$[0.0052]^{* * *}$} & {$[0.0051]^{* * *}$} & {$[0.0051]^{* *}$} & {$[0.0048]$} & {$[0.0048]$} & {$[0.0048]$} & {$[0.0047]$} & {$[0.0047]$} & {$[0.0047]$} \\
\hline \multirow{2}{*}{ SeconEduc } & 0.2188 & 0.1425 & 0.2634 & 0.1257 & 0.1450 & 0.1454 & 0.1112 & 0.1403 & 0.1382 \\
\hline & {$[0.0215]^{* * *}$} & {$[0.0190]^{* * *}$} & {$[0.0233]^{* * *}$} & {$[0.0205]^{* * *}$} & {$[0.0189]^{* * *}$} & {$[0.0194]^{* * *}$} & {$[0.0200]^{* * *}$} & {$[0.0188]^{* * *}$} & {$[0.0194]^{* * *}$} \\
\hline \multirow{2}{*}{ HighEduc } & 0.4728 & 0.2710 & 0.4499 & 0.2510 & 0.2679 & 0.2618 & 0.2245 & 0.2552 & 0.2441 \\
\hline & {$[0.0327]^{* * *}$} & {$[0.0211]^{* * *}$} & {$[0.0296]^{* * *}$} & {$[0.0314]^{* * *}$} & {$[0.0210]^{* * *}$} & {$[0.0237]^{* * *}$} & {$[0.0302] * * *$} & {$[0.0208]^{* * *}$} & {$[0.0246]^{* * *}$} \\
\hline \multirow{2}{*}{ Children $<16$} & -0.0233 & -0.0368 & -0.0360 & -0.0320 & -0.0401 & -0.0378 & -0.0336 & -0.0435 & -0.0392 \\
\hline & {$[0.0094]^{* *}$} & {$[0.0094]^{* * *}$} & {$[0.0094]^{* * *}$} & {$[0.0093]^{* * *}$} & {$[0.0094]^{* * *}$} & {$[0.0094]^{* * *}$} & {$[0.0094]^{* * *}$} & {$[0.0094]^{* * *}$} & {$[0.0094]^{* * *}$} \\
\hline \multirow{2}{*}{ Illness } & -0.0517 & -0.0653 & -0.0655 & -0.1160 & -0.1229 & -0.1211 & -0.1152 & -0.1219 & -0.1209 \\
\hline & {$[0.0160]^{* * *}$} & {$[0.0155]^{* * *}$} & {$[0.0155]^{* * *}$} & {$[0.0137]^{* * *}$} & {$[0.0137]^{* * *}$} & {$[0.0137]^{* * *}$} & {$[0.0137]^{* * *}$} & {$[0.0137]^{* * *}$} & {$[0.0137]^{* * *}$} \\
\hline \multirow{2}{*}{ PublicSector } & 0.0492 & 0.0837 & 0.0740 & 0.1582 & 0.1544 & 0.1541 & 0.1556 & 0.1450 & 0.1512 \\
\hline & {$[0.0278]^{*}$} & {$[0.0255]^{* * *}$} & {$[0.0262]^{* * *}$} & {$[0.0236]^{* * *}$} & {$[0.0235]^{* * *}$} & {$[0.0236]^{* * *}$} & {$[0.0235]^{* * *}$} & {$[0.0235]^{* * *}$} & {$[0.0235]^{* * *}$} \\
\hline \multirow{2}{*}{ FullTime } & 0.0631 & 0.1682 & 0.1627 & 0.3242 & 0.3776 & 0.3689 & 0.3223 & 0.3706 & 0.3679 \\
\hline & {$[0.0415]$} & {$[0.0366]^{* * *}$} & {$[0.0370]^{* * *}$} & {$[0.0243]^{* * *}$} & {$[0.0245]^{* * *}$} & {$[0.0245]^{* * *}$} & {$[0.0243]^{* * *}$} & {$[0.0244]^{* * *}$} & {$[0.0244]^{* * *}$} \\
\hline \multirow{2}{*}{ Dummy PrivTransf } & -0.2190 & -0.2327 & -0.2306 & -0.2881 & -0.2768 & -0.2751 & -0.2892 & -0.2799 & -0.2759 \\
\hline & {$[0.0428]^{* * *}$} & {$[0.0424]^{* * *}$} & {$[0.0424]^{* * *}$} & {$[0.0418]^{* * *}$} & {$[0.0419]^{* * *}$} & {$[0.0419]^{* * *}$} & {$[0.0418]^{* * *}$} & {$[0.0419]^{* * *}$} & {$[0.0419]^{* * *}$} \\
\hline \multirow{2}{*}{ Dummy PubTransf ${ }^{i}$} & -0.4059 & 0.1303 & 0.1075 & -0.2712 & 0.2293 & 0.1660 & -0.2694 & 0.2361 & 0.1725 \\
\hline & {$[0.0544]^{* * *}$} & {$[0.0438]^{* * *}$} & {$[0.0434]^{* *}$} & {$[0.0521]^{* * *}$} & {$[0.0445]^{* * *}$} & {$[0.0434]^{* * *}$} & {$[0.0521]^{* * *}$} & {$[0.0443]^{* * *}$} & {$[0.0434]^{* * *}$} \\
\hline \multirow{2}{*}{ Dummy Taxes ${ }^{\mathrm{i}}$} & -0.1478 & -0.1039 & -0.1110 & -0.0945 & -0.0653 & -0.0658 & -0.0938 & -0.0630 & -0.0647 \\
\hline & {$[0.0219]^{* * *}$} & {$[0.0214]^{* * *}$} & {$[0.0215]^{* * *}$} & {$[0.0209]^{* * *}$} & {$[0.0207]^{* * *}$} & {$[0.0208]^{* * *}$} & {$[0.0209]^{* * *}$} & {$[0.0207]^{* * *}$} & {$[0.0207]^{* * *}$} \\
\hline \multirow{2}{*}{ EqNetHousInc } & 0.5229 & 0.5526 & 0.5501 & 0.6313 & 0.6182 & 0.6304 & 0.6140 & 0.5839 & 0.6221 \\
\hline & {$[0.0258]^{* * *}$} & {$[0.0263]^{* * *}$} & {$[0.0258]^{* * *}$} & {$[0.0259]^{* * *}$} & {$[0.0260]^{* * *}$} & {$[0.0256]^{* * *}$} & {$[0.0267]^{* * *}$} & {$[0.0269]^{* * *}$} & {$[0.0263]^{* * *}$} \\
\hline Denrivation & -2.0097 & -1.5430 & -1.5894 & 0.6163 & 2.7474 & 0.4244 & 0.7546 & 1.4641 & 0.4595 \\
\hline Deprivation & {$[0.2566]^{* * *}$} & {$[0.2090]^{* * *}$} & {$[0.2133]^{* * *}$} & {$[0.4331]$} & {$[0.5346]^{* * *}$} & {$[0.3274]$} & {$[0.2005]^{* * *}$} & {$[0.2241]^{* * *}$} & {$[0.1668]^{* * *}$} \\
\hline Deprivation $^{2}$ & & & & -1.9318 & -4.3240 & -0.6034 & -0.4048 & -0.6818 & -0.1475 \\
\hline Deppivationi & & & & {$[0.3539] * * *$} & {$[0.9875]^{* * *}$} & {$[0.2853]^{* *}$} & {$[0.0736]^{* * *}$} & {$[0.1754]^{* * *}$} & {$[0.0528]^{* * *}$} \\
\hline Intra-group Variance & & & & $\begin{array}{l}-1.0599 \\
{[262711}\end{array}$ & 0.4186 & 0.5476 & $\begin{array}{c}-0.9301 \\
{[0.4306] * *}\end{array}$ & -0.6202 & $\begin{array}{l}-0.1936 \\
{[02308]}\end{array}$ \\
\hline $\begin{array}{l}\text { Log Likelihood } \\
\text { Rho }\end{array}$ & & & & & [0.1012] & {$[1.2501]$} & & & \\
\hline Number of Observations & 62852 & 62878 & 62852 & 62852 & 62878 & 62852 & 62852 & 62878 & 62852 \\
\hline
\end{tabular}


Table 9.a. Benefits to Increase Income Satisfaction (6 groups)

\begin{tabular}{cccccccc}
\hline Satisf levels & Priv Transf & Unemp Transf & Ret Transf & Wid Transf & Mat Transf & Illness Transf School Transf \\
\hline $1-2$ & 21049.85 & 599222.36 & 10256.44 & 22831.61 & 25758.02 & 20230.04 & 33322.81 \\
$2-3$ & 20869.63 & 594092.01 & 10168.63 & 22636.13 & 25537.48 & 20056.84 & 33037.51 \\
$3-4$ & 21992.69 & 626062.15 & 10715.84 & 23854.26 & 26911.74 & 21136.16 & 34815.37 \\
$4-5$ & 29379.63 & 836344.67 & 14315.09 & 31866.45 & 35950.89 & 28235.40 & 46509.21 \\
\hline
\end{tabular}

Table 9.b. Benefits to Increase Income Satisfaction (8 groups)

\begin{tabular}{cccccccc}
\hline Satisf levels & Priv Transf & Unemp Transf & Ret Transf & Wid Transf & Mat Transf & \multicolumn{2}{c}{ Illness Transf School Transf } \\
\hline $1-2$ & 19972.78 & 304612.66 & 10243.65 & 22972.95 & 27199.89 & 19598.62 & 32906.14 \\
$2-3$ & 19815.29 & 302210.79 & 10162.88 & 22791.80 & 26985.42 & 19444.09 & 32646.68 \\
$3-4$ & 20875.83 & 318385.49 & 10706.81 & 24011.65 & 28429.71 & 20484.76 & 34393.97 \\
$4-5$ & 27892.86 & 425405.04 & 14305.71 & 32082.73 & 37985.85 & 27370.34 & 45954.88 \\
\hline
\end{tabular}

Table 9.c. Benefits to Increase Income Satisfaction (24 groups)

\begin{tabular}{|c|c|c|c|c|c|c|c|}
\hline Satisf levels & Priv Transf & Unemp Transf & Ret Transf & Wid Transf & Mat Transf & Illness Transf & School Transf \\
\hline $1-2$ & 20270.56 & 354518.75 & 10333.65 & 23142.13 & 26369.48 & 20093.28 & 3287.29 \\
\hline $2-3$ & 20095.25 & 351452.75 & 10244.28 & 22941.99 & 26141.43 & 19919 & 3258.86 \\
\hline $3-4$ & 21175.99 & 370354.16 & 10795.22 & 24175.82 & 27547.34 & 20990.79 & 3434.12 \\
\hline $4-5$ & 28299.05 & 494931.80 & 14426.46 & 32307.95 & 36813.55 & 28051.55 & 4589.27 \\
\hline
\end{tabular}

